\title{
Out-of-Autoclave Prepreg Processing
}

\author{
Pascal Hubert ${ }^{1}$, Timotei Centea ${ }^{2}$, Lessa Grunefelder ${ }^{3}$, Steven $\mathrm{Nutt}^{3}$, James $\mathrm{Kratz}^{4}$, Arthur Levy \\ ${ }^{1}$ Department of Mechanical Engineering, McGill University, 817 Sherbrooke Street West, \\ Montreal, QC, Canada, H3A 0C3, pascal.hubert@mcgill.ca \\ ${ }^{2}$ M.C. Gill Composites Center, Department of Aerospace and Mechanical Engineering, \\ University of Southern California, Los Angeles, CA 90089-0214, USA, centea@usc.edu \\ ${ }^{3}$ M.C. Gill Composites Center, Department of Chemical Engineering and Materials Science, \\ University of Southern California, Los Angeles, CA 90089-0214, USA, grunenfe@usc.edu, \\ nutt@usc.edu \\ ${ }^{4}$ Advanced Composites Centre for Innovation and Science, University of Bristol, Queen's \\ Building, University Walk, Bristol BS8 1TR, UK, james.kratz@bristol.ac.uk \\ ${ }^{5}$ Laboratoire de Thermique et Energie de Nantes, Université de Nantes, rue Christian Pauc, \\ 44306 Nantes Cedex 3, France, arthur.levy@univ-nantes.fr
}

\begin{abstract}
The objective of this chapter is to provide an overview of the processing aspects of out-ofautoclave (OOA) prepregs. This chapter serves as a design guideline for the definition of tooling, bagging configuration and processing conditions for making parts with OOA prepregs. The first section presents an overview of the OOA materials, including their application, resins and fibres. OOA prepreg impregnation techniques are then discussed and typical properties of OOA composites are summarized. The second section covers OOA prepreg characterization methods, techniques to measure resin impregnation, thermochemistry, out-time, permeability, and bulk factor are presented. The third section describes the infrastructure used to cure OOA prepregs, such as ovens, heating systems, tooling and process diagnostic tools. The fourth section provides basic processing guidelines, covering bagging configuration, debulking methods and cure cycles to make simple monolithic OOA laminates, while sections five and six provide processing guidelines for sandwich panels and complex shape laminates. The cost analysis of the manufacturing process with OOA prepregs is reviewed in section seven. Finally, section eight discusses future developments for OOA prepreg materials and processes.
\end{abstract}

\section{Keywords}

Out-of-autoclave, prepregs, consolidation, voids, honeycomb, guidelines, design, compaction, curing 


\section{Overview}

Out-of-autoclave (OOA) processing refers to the manufacture of composite parts with low defect levels and high performance without a pressurized autoclave vessel. OOA processing offers several potential advantages over traditional autoclave cure, including lower capital acquisition and operating costs, use of a wider range of cure infrastructure, tooling, and materials, a broader subcontractor base, and the capacity to fabricate large, integrated structures whose size exceeds that of available pressure vessels. However, OOA processing also presents several challenges: materials and methods are often more complex than their autoclave counterparts and, in the absence of high pressure, process phenomena are more sensitive to unwanted deviations.

Many composite manufacturing processes can be classified as "out-of-autoclave." However, the focus of this chapter is late-generation vacuum bag-only (VBO) prepregs intended for high performance applications. The materials and methods discussed below have been developed to achieve autoclave quality via low pressure cure in conventional ovens. Therefore, they exhibit similarities to traditional autoclave cure while possessing important differentiating features. Note that early iterations of VBO materials, vacuum bag cure of autoclave prepregs, and other nonautoclave methods (e.g. liquid/press moulding, Quickstep) are omitted from this discussion.

This chapter provides an overview of the science and engineering of OOA prepreg processing. The major characteristics of OOA materials are described, and methods for characterizing their key properties are presented. Process design is discussed in terms of key infrastructure and sciencebased guidelines to optimize cure. Specific considerations associated with the processing of cocured sandwich panels and complex shape parts are also analyzed. Finally, cost studies for OOA prepreg processing are discussed, and future developments are addressed. Overall, the chapter provides a concise synthesis of current knowledge of OOA prepreg processing, and can serve as a practical guide for designing an OOA manufacturing process.

\subsection{Resin Properties}

Successful OOA prepreg cure requires intelligent selection of resin system and fibre bed architecture and, critically, resin and fibre compatibility during processing. While much of the literature on OOA prepreg relates to carbon fibre-epoxy systems, theoretically any type of resin can be utilized in the fabrication of OOA prepregs.

The key requirements for OOA cure are well tailored cure kinetics and rheology and the capacity for robust manufacturing. For these reasons, addition-curing resins are more compatible with VBO processing than condensation-curing systems, owing to the significant cure-induced volatiles observed in the latter case. Generally, OOA resin systems must also display sufficient roomtemperature out-life and tack to enable the layup of large parts (typically, 3-4 weeks working life), low solvent content, and low moisture uptake under ambient conditions. Because cost reduction is a major benefit of OOA cure, resins allowing low temperature cure $(<120 \mathrm{C})$ followed by freestanding post-cure are desirable, as they enable the use of inexpensive tooling materials and limit volatile formation.

The resin cure kinetics and rheology are perhaps the most important factors governing defect formation. As discussed in Section 3.1, OOA prepregs are partially impregnated by design to facilitate removal of entrapped air during a room temperature vacuum hold. As a result, the resin 
viscosity at room temperature must be sufficiently high to preclude "cold flow" and avoid premature sealing of air evacuation channels. However, the resin must also achieve a sufficiently low viscosity during the cure cycle to ensure that the fibre bed is fully saturated prior to gelation and final cure. Finally, aerospace applications (and other high performance uses) typically require no-bleed material systems in order to maintain strict control over resin content and retain resin pressure. Hence, the viscosity of an OOA prepreg resin must remain sufficiently high to eliminate the risk of significant bleed, while the resin content must be carefully controlled to ensure that there is sufficient resin to wet out all initial dry areas while still maintaining a high final fibre volume fraction. Since resin infiltration into the fibre bed is also influenced by the reinforcement permeability, the resin cure kinetics and viscosity must therefore be optimized relative to the fibre bed architectures of interest to create a robust, self-compatible OOA prepreg.

To date, most VBO prepreg systems have consisted of toughened epoxy resins. However, commercial products are available for other resin families, including cyanate ester, bismaleimide and benzoxazine. The mechanical property equivalence of OOA systems to benchmark autoclave materials is discussed in Section 1.4.

\subsection{Fibre Bed Properties}

Theoretically, any fibre bed architecture can be used for OOA prepreg cure if, as with the resin system, key requirements are met. To date, a range of fibre types have been utilized in VBO prepregs, though glass and carbon fibre are most common. For high performance OOA prepregs used in aerospace applications, typical carbon fibre beds consist of unidirectional tapes (approx. $\left.145 \mathrm{~g} / \mathrm{m}^{2}\right)$ and woven fabrics $\left(190-370 \mathrm{~g} / \mathrm{m}^{2}\right)$ with $3 \mathrm{~K}$ to $12 \mathrm{~K}$ tows. Table 1 describes the typical characteristics of fibre bed architectures commonly discussed in the published literature.

The major requirement for fibre bed selection is compatibility with the resin system. Namely, the fibre volume fraction and permeability of the reinforcement (and resin content of the prepreg) must combine to allow partial impregnation in the initial state and full saturation during cure, prior to resin gelation. However, the fibre bed can also affect the following process issues:

- Cured ply thickness: Fibre beds with higher areal weights can facilitate layup, since thickness build-up requires fewer layers. However, heavier fibre beds can exhibit a higher bulk factor (or ratio of initial to final thickness), and can be more difficult to compact under a process pressure of only $0.1 \mathrm{MPa}$.

- $\quad$ Air entrapment: Fibre beds with uneven surface morphologies (e.g. woven fabrics) are more likely to entrap air in inter-ply regions (or at the tool/part interface) than fibre beds with smooth morphologies (e.g. unidirectional tapes). During OOA cure, a higher level of entrapped air can lead to higher porosity within the cured part, unless the air is fully evacuated under vacuum

- Permeability: The effective in-plane and transverse prepreg air permeabilities depend on the intrinsic permeability of the fibre bed. In all cases, the permeability tensor is influenced by the fibre volume fraction. For woven fabrics, the permeability is also affected by the dual-scale construction of the reinforcement, and the relative amount of micro-pore space (within tows) and macro-pore space (between tows).

- Drapability: Unidirectional reinforcements and woven fabrics with denser weaves are typically less drapable than fabrics with a looser weave. In the absence of autoclave 
pressure, such materials may be difficult to conform to tool geometries with tight curvatures.

Table 1 Typical fibre bed architectures used to produce OOA prepregs, and key characteristics.

\begin{tabular}{|c|c|c|c|c|}
\hline \multirow[t]{2}{*}{$\begin{array}{l}\text { Reinforcemen } \\
\text { Type }\end{array}$} & & & & \\
\hline & $\begin{array}{l}\text { Unidirectional } \\
\left(145 \mathrm{~g} / \mathrm{m}^{2}\right)\end{array}$ & $\begin{array}{c}\text { Plain weave } \\
\left(190 \mathrm{~g} / \mathrm{m}^{2}\right)\end{array}$ & $\begin{array}{l}\text { 2x2 Twill Weave } \\
\left(370 \mathrm{~g} / \mathrm{m}^{2}\right)\end{array}$ & $\begin{array}{l}8 \text { Harness Satin } \\
\left(375 \mathrm{~g} / \mathrm{m}^{2}\right)\end{array}$ \\
\hline $\begin{array}{l}\text { Cured Ply } \\
\text { Thickness } \\
\text { (Prepreg) }\end{array}$ & $0.14 \mathrm{~mm}$ & $0.19 \mathrm{~mm}$ & $0.38 \mathrm{~mm}$ & $0.37 \mathrm{~mm}$ \\
\hline $\begin{array}{l}\text { Waviness of } \\
\text { Fabric } \\
\text { Architecture }\end{array}$ & Low & High & $\begin{array}{c}\text { Intermediate to } \\
\text { High }\end{array}$ & Intermediate \\
\hline $\begin{array}{l}\text { Dual-Scale } \\
\text { Porosity }\end{array}$ & No & Yes & Yes & Yes \\
\hline Drapability & Low & Intermediate & Intermediate & High \\
\hline
\end{tabular}

\subsection{Prepreg Properties}

Out-of-autoclave prepregs possess a partially impregnated microstructure that imparts in-plane (and sometimes transverse) permeability. This distinguishing characteristic allows air evacuation and, ideally, the production of low-porosity parts in the absence of autoclave pressure. However, it also affects many other aspects of the manufacturing process. The methods employed to fabricate OOA prepregs, the distinguishing microstructural features of these materials, and the evolution of the prepreg microstructure are discussed below.

\subsubsection{Prepregging}

Prepregs are created by impregnating a fibre bed with liquid resin. The resin distribution, extent of fibre bed saturation, and properties of the fibre and resin phases are typically optimized to balance processability with the properties and performance of the fabricated part.

Prepregs can be produced using solution, hot-melt or direct coating processes. Solution impregnation consists of saturating the fibre bed by immersing it in a bath containing the resin matrix and a low-viscosity solvent, and heating it post-immersion to remove the vaporized solvent. Solution impregnation can ensure full saturation of the fibre bed, but residual solvent can lead to void formation during cure. 
Hot-melt impregnation begins with the production of resin films with accurate, uniform thickness. Next, these films are applied to one or both sides of the fibre bed, and driven to infiltrate via heated compaction rollers. By separating resin film production from impregnation, the hot-melt process enables accurate control of resin content and extent of impregnation. As explained below, most OOA prepregs are produced using the hot-melt prepregging.

Finally, prepregs can be produced by direct coating of the fibre bed. First, resin is distributed onto a heated coating roller, with a doctoring blade used to control thickness. Then, the roller is used to transfer the resin to the fibre bed. Direct coating is a simple, one-step process, requiring neither solvents nor the fabrication of an intermediate film. However, the resin distribution patterns depend on the fibre bed surface topology, and accurate control of resin content can be challenging. For this reason, hot-melt or solvent methods are typically used for aerospace-grade prepregs.

Autoclave prepregs are typically assumed to be fully impregnated. Autoclave cure relies on high consolidation pressure (0.3 - 0.8 MPa) to prevent void nucleation and growth. Thus, for autoclave prepregs, full saturation reduces the likelihood of dry spots and other defects arising from insufficient resin flow, and contributes to the formation of a high-quality, low-defect microstructure. Moreover, full saturation also reduces the bulk factor (difference between final and initial thickness) of the prepreg, particularly if no bleed is expected, increasing handling and drapability, and reducing the risk of wrinkling in high-curvature regions.

Conversely, OOA prepregs possess a partially-impregnated microstructure that includes both dry and resin-rich regions (Figure 1). The maximum consolidation pressure available during OOA cure $(0.1 \mathrm{MPa})$ is insufficient to prevent void nucleation and growth. Therefore, the processing of parts with low defect levels requires the evacuation of entrapped air, vaporized moisture, and/or other volatiles present in the laminate prior to resin gelation. The dry regions of the initial prepreg microstructure form a permeable internal network that allows gas transport during the initial, lowtemperature stages of cure. Then, at high temperature, they are infiltrated by resin from external resin-rich regions.

Several commercially-available prepregs have been analyzed using optical methods, including Xray computed microtomography and light microscopy (Centea, Hubert (2011), Louis, Hsiao, Fernlund (2010), Grunenfelder, Nutt (2011), Wysocki, Larsson, Toll (2009)). The results suggest that, for prepregs based on woven fabrics, the dry evacuation channels consist of the fibre tow cores, while unidirectional tapes possess a dry midplane within each layer (Figure 1, B and C). 


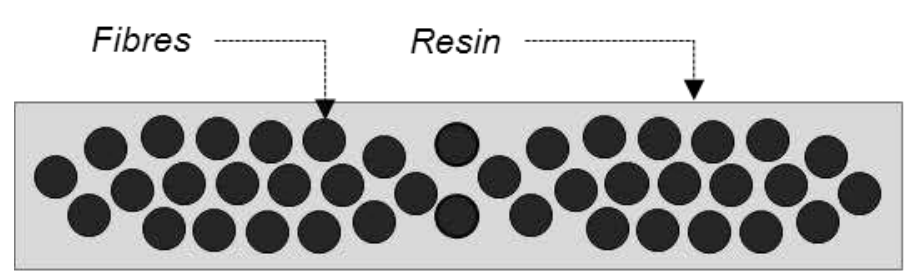

A) Autoclave Prepreg

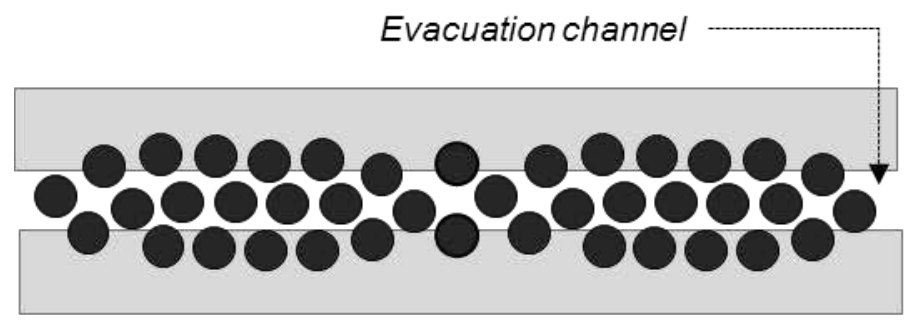

B) Out-of-Autoclave Prepreg

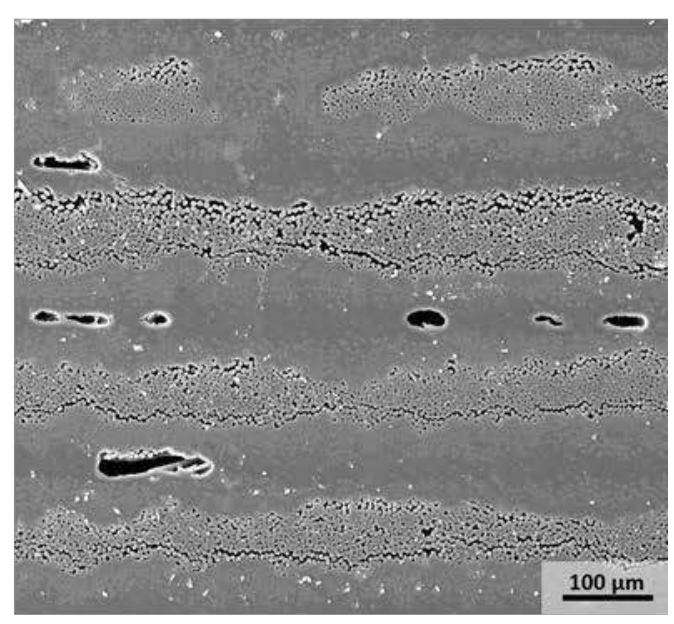

C) SEM Micrograph (4 plies, uncured)

Figure 1 Schematics of the impregnation paradigms of unidirectional (A) autoclave prepregs and (B) OOA prepregs, and (C) SEM micrograph of a four-layer laminate of uncured unidirectional prepreg (Cytec Cycom 5320-1, T40-800B).

\subsubsection{Consolidation}

The consolidation of OOA prepregs is a three-stage process consisting of coupled fibre bed compaction, air evacuation, and resin flow. The three stages of consolidation are shown in Figure 2 in terms of thickness, relative to a simple temperature cycle, and in Figure 3 in terms of the prepreg microstructure.

During Stage I, a room-temperature vacuum hold is used to evacuate the vacuum bag, compact the part, and impose an internal pressure gradient that drives gas evacuation from the internal void spaces of the laminate towards the vacuum source (Figure 3, A and B). Consequently, the fibre volume fraction increases with compaction while the void fraction and the in-plane permeability of the prepreg decrease. During Stage I, resin flow is typically limited due to high roomtemperature viscosity of the matrix.

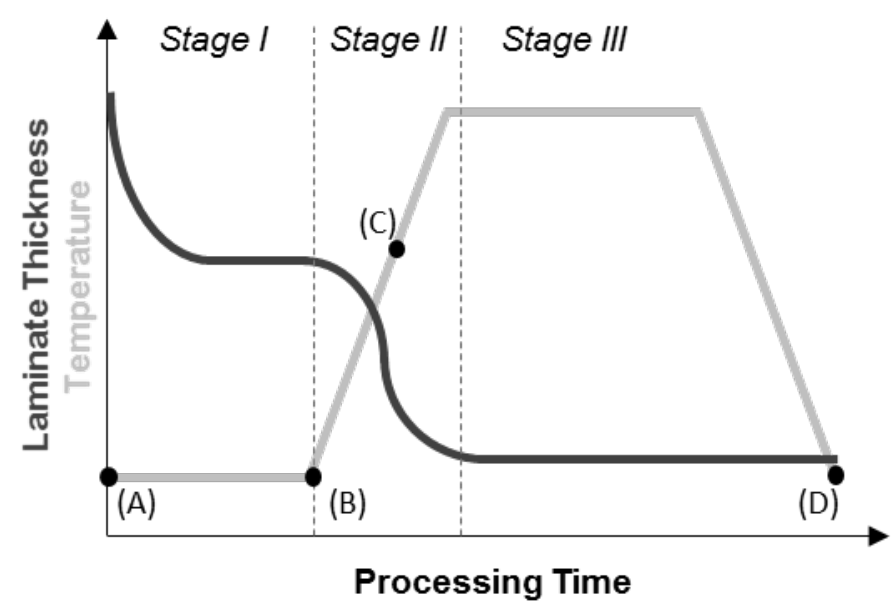


Figure 2 Schematic of the three stages of consolidation versus temperature and laminate thickness. The microstructure of the OOA prepreg at points A-D is shown in Figure 3.

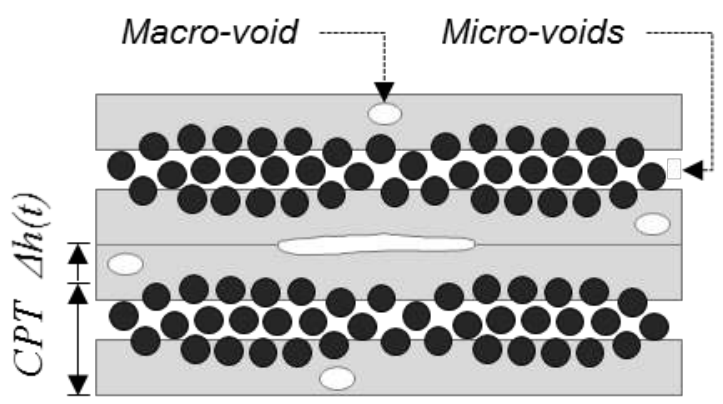

A) Layup

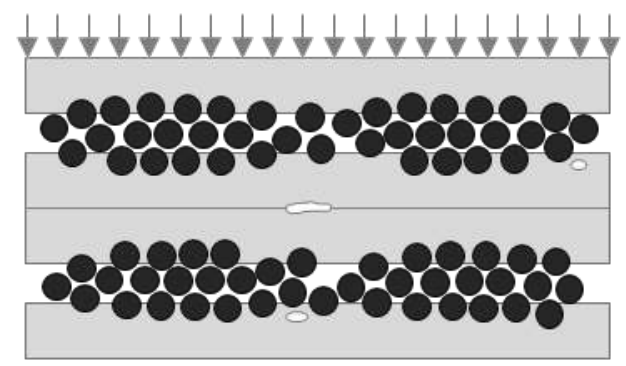

B) RT Vacuum Hold

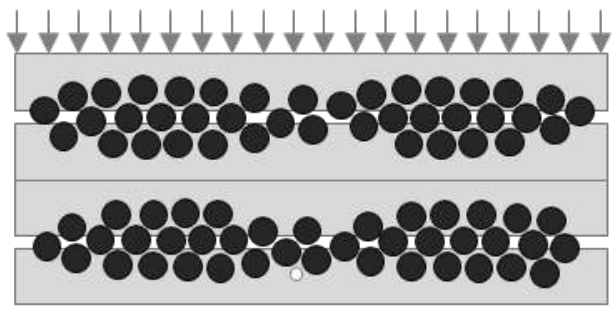

C) Heated Cure

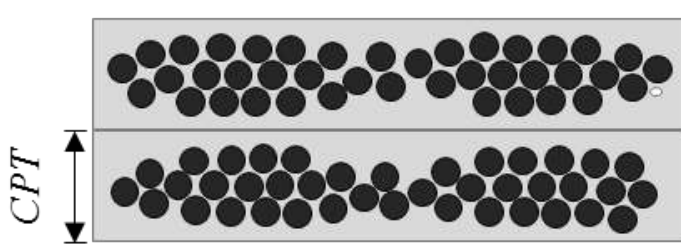

D) Cured Part

Figure 3: Schematics of the microstructure of an OOA prepreg during (A) layup, (B) room temperature vacuum holding, (C) heated cure, and (D) post-cure. CPT denotes the cured ply thickness.

During Stage II, the part is heated, decreasing the resin viscosity and enabling the progressive impregnation of the fibre bed (Figure 3, C). Locally, the resin flows into the dry fibre tows, and saturates any remaining macro-pore or interlaminar spaces. Globally, the prepreg permeability decreases as the network of dry channels is interrupted and eventually eliminated, and the laminate thickness undergoes a second marked decrease, and tends towards the cured ply thickness as the fraction of unsaturated pore space decreases to, ideally, zero. It should be noted that, for the OOA prepregs studied in published literature, impregnation is largely complete by the end of the first temperature ramp. This rate of impregnation implies that once the cure dwell temperature has been reached, the dry evacuation channels are saturated, and the in-plane permeability of the prepreg is minimal, precluding large-scale air evacuation. However, bubble migration within the lowviscosity resin, towards low-pressure regions, is still possible.

Finally, during Stage III, the resin undergoes gelation and vitrification as the thermosetting cure reaction evolves and completes. At the end of Stage III, the laminate microstructure is typically fixed (Figure 3, D), since the matrix is not expected to devitrify during post-cure.

\subsubsection{Defect Formation}

The three-stage consolidation process outlined above allows OOA prepreg processing to achieve autoclave-level microstructural quality. However, the fibre bed, air evacuation, and resin flow 
phenomena are also sensitive to changes in material and process conditions. As a result, suboptimal consolidation can result in defects.

The most common type of defect during low-pressure cure is porosity (Table 2). During OOA prepreg processing, voids can be classified as gas- or flow-induced. Gas-induced porosity forms when the pressure within a nucleated void exceeds the surrounding resin pressure. Primary causes consist of un-evacuated air and moisture absorbed by the resin prior to cure (Grunenfelder, Nutt (2010)). However, other factors have been shown to increase defect levels, including reduced vacuum quality, reduced ambient pressure, and restricted air evacuation (Centea, Hubert (2014)). Gas-induced voids most often manifest as randomly-distributed quasi-elliptical bubbles within resin-rich regions or between layers (Figure 4, A), though they can also be found within fibre tows in cases of reduced vacuum (Centea, Hubert (2014)). Moreover, porosity caused by entrapped air can also form on the tool-side surface of laminates (Hamill, Centea, Nutt (2015)).

Flow-induced porosity forms due to incomplete resin infiltration into the dry regions of the fibre bed. The most common cause is increased resin viscosity due to exposure to ambient conditions (out-time) (Grunenfelder, Centea, Hubert, Nutt (2013)). However, for material with elevated outtimes, low-temperature cure cycles can also lead to insufficient flow (Centea, Kratz, Hubert (2012)). Flow-induced voids manifest as pervasive dry areas within the fibre tow cores (Figure 4, B), since they are a direct consequence of the evacuation channels present within the initial prepreg microstructure.

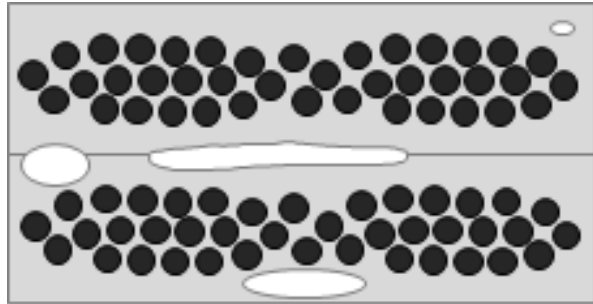

A) Macro-Voids

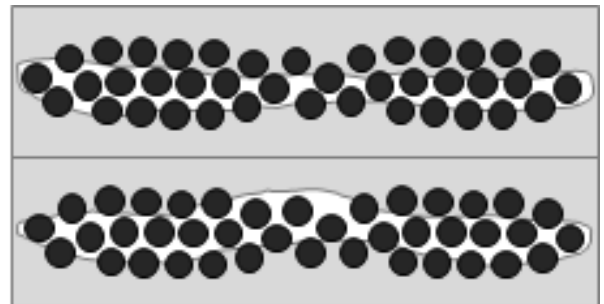

B) Micro-Voids

Figure 4: Schematics of (A) macro-voids and (B) micro-voids that can be induced by process deviations during OOA prepreg cure.

Table 2 Major sources of gas-induced and flow-induced porosity. The symbol $\Uparrow$ indicates that an increase in the factor leads to an increase in porosity.

\begin{tabular}{|l|l|}
\hline Sources of Gas-Induced Porosity & Sources of Flow-Induced Porosity \\
\hline$\Uparrow$ Entrapped air & $\Uparrow$ Out-time \\
$\Uparrow$ Moisture absorption and vapourization & $\Downarrow$ Cure temperature \\
$\Downarrow$ Vacuum quality & \\
$\Downarrow$ Air evacuation & \\
$\Uparrow$ Tack & \\
\hline
\end{tabular}




\subsection{Mechanical Property Equivalence}

The major motivation for the development of OOA prepreg processing was to enable fabrication of autoclave-quality parts without the constraints and costs associated with autoclave cure. To date, several publications have reported autoclave-equivalent mechanical properties for a range of OOA prepreg systems. Furthermore, several OOA prepreg materials have also been qualified by the National Center for Advanced Materials Performance (NCAMP). Figure 5 presents, as an example, data for two carbon fibre/epoxy OOA prepreg systems and a standard autoclave material.

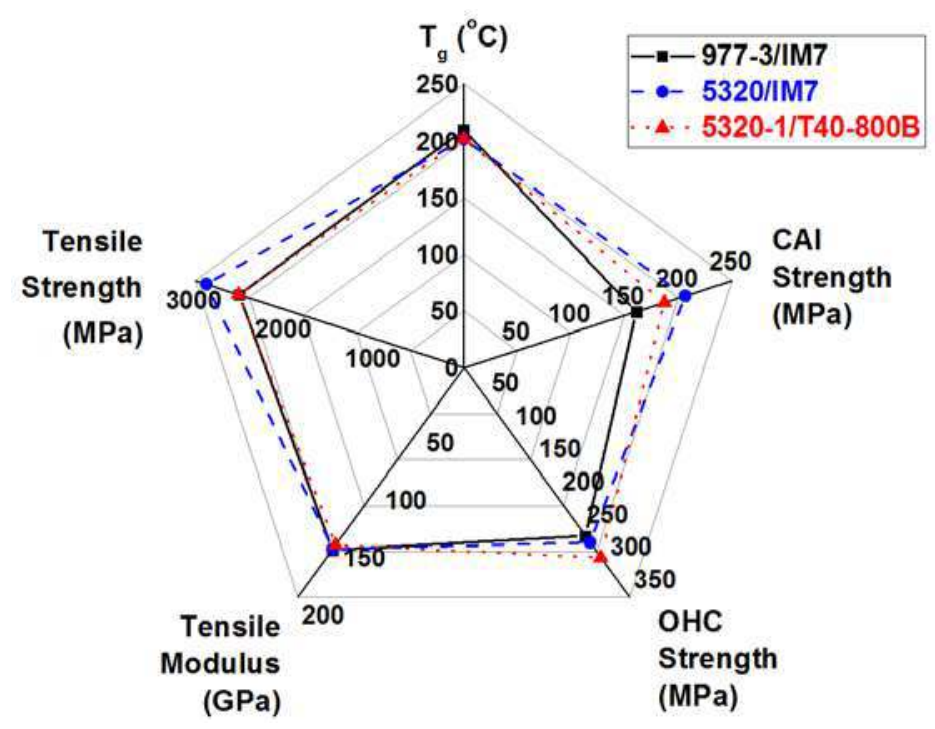

Figure 5 Mechanical performance of an autoclave prepreg system (Cytec 977-3/IM7) and two OOA prepreg systems (5320/IM7 and 5320-1/T40-800B) (Lucas, Howard, Senger (2010)).

The critical difference between autoclave and OOA processing is therefore not associated with the intrinsic mechanical properties of the constituent materials but the capacity to consistently produce parts with the required microstructural, dimensional, and mechanical performance specifications. Upon successful cure, OOA prepregs can achieve autoclave-equivalent behaviour. However, as highlighted in this chapter, VBO curing is more sensitive to deviations in material properties and process conditions, and therefore more vulnerable to defects that can, in theory, degrade mechanical performance.

\section{Prepreg Characterization}

\subsection{Resin Thermochemical Properties}

Figure 6 presents a methodical approach used in order to investigate the thermochemical properties of OOA thermoset resins (Khoun, Centea, Hubert (2010)). First, thermal stability tests are conducted to determine the resin temperature processing window (step 1). The curing behaviour is then investigated in order to obtain the evolution of the degree-of-cure, $\alpha$, as a function of time and temperature (step 2). The resin rheological behaviour (step 3a) and the glass transition temperature (step $3 \mathrm{~b}$ ), $\mathrm{Tg}$, are then measured as a function of the degree-of-cure. Next, knowing the resin rheological behaviour, the cure shrinkage, $\varepsilon v$, is determined as a function of the degreeof-cure at the gel point, $\alpha_{\text {gel }}$ (step 4a). The coefficient of thermal expansion (step $4 \mathrm{~b}$ ) and the resin 
modulus (step 4c) are expressed as a function of the glass transition temperature. Finally, the material constitutive models can be implemented in multiphysical simulation software (e.g. RAVEN, COMPRO) (step 5) to predict the final properties as a function of the cure cycle used.

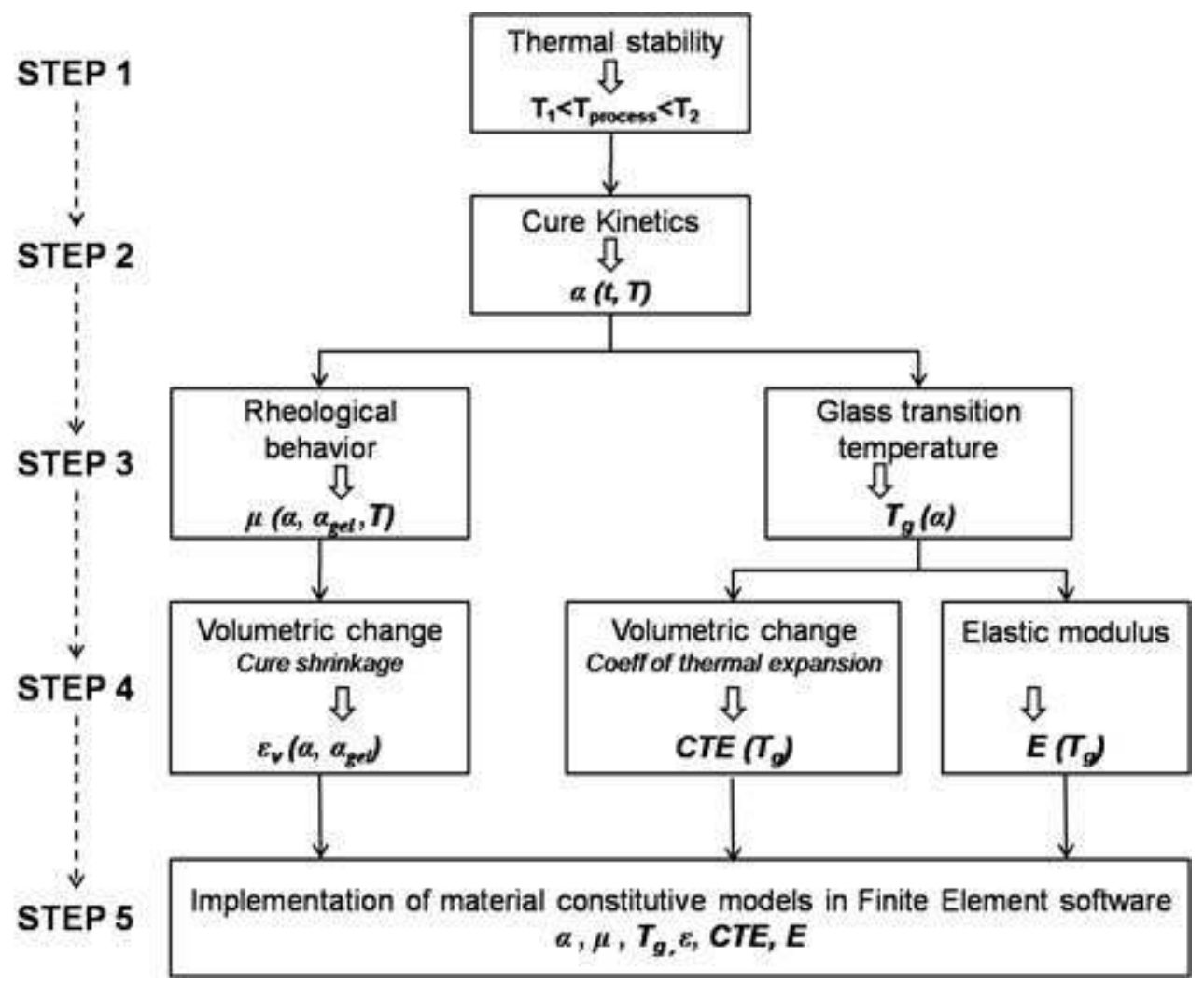

Figure 6 Characterization procedure for thermoset resins.

(Step 1) Thermal stability tests are carried out using a Thermal Gravimetric Analyzer (TGA). A temperature ramp at $20^{\circ} \mathrm{C} / \mathrm{min}$ from $25^{\circ} \mathrm{C}$ to $700^{\circ} \mathrm{C}$ is applied to a resin sample. The sample is under nitrogen from $25^{\circ} \mathrm{C}$ to $550^{\circ} \mathrm{C}$ and air from $550^{\circ} \mathrm{C}$ to $700^{\circ} \mathrm{C}$. The maximum resin temperature corresponds typically to a sample mass loss of $2 \%$.

(Step 2) The resin cure kinetics is measured with a Modulated Differential Scanning Calorimeter (MDSC). Dynamic scans with heating rates of $1^{\circ} \mathrm{C} / \mathrm{min}$ and $2^{\circ} \mathrm{C} / \mathrm{min}$, from $25^{\circ} \mathrm{C}$ to the maximum resin temperature, and isothermal scans at temperatures chosen from typical cure cycles for the resin, are performed. The dynamic scans measure the total heat of reaction released during the cure whereas isothermal scans are used to monitor the heat flow during a series of isothermal cures. The measured heat generated by the resin is then converted into cure rate based on the assumption that the rate of reaction is proportional to the rate of the heat flow. The cure rate can be expressed as a function of the degree-of-cure and compared to existing cure kinetics models (Boyard (2016), Kamal, Sourour (1973). Bailleul, Delaunay, Jarny (1996)). Cure kinetics models for OOA resins were developed for 5320-1 (Kim et al (2014)), and 5320 and MTM45-1 (Kratz et al (2013)).

(Step 3a) Rheological measurements are performed with a parallel plate rheometer. Dynamic scans at heating rates of $1-3^{\circ} \mathrm{C} / \mathrm{min}$ and isothermal scans at temperatures chosen from 
typical cure cycles for the resin. To characterize the rheological behaviour of the resin, a model taking into account the influence of both the temperature and the degree-ofcure is used.

(Step 3b) The glass transition temperature $\left(\mathrm{T}_{\mathrm{g}}\right)$ can be measured by different techniques. One of the most common methods uses MDSC, where the $T_{\mathrm{g}}$ is identified by a step change in the specific heat. Thermo Mechanical Analysis (TMA) is another widely used method of measuring the $\mathrm{T}_{\mathrm{g}}$. An increase in the coefficient of thermal expansion is noticed when the resin progresses from its glassy state to its rubbery state with a temperature ramp. Rectangular solid sample tested on a rheometer in torsion mode can also be used. The glass transition temperature is determined by observing the three modulus based indicators: the onset of a sharp drop in the storage modulus $\mathrm{G}^{\prime}$, the peak in the loss modulus G" and the peak in the $\tan \delta$. The evolution of the $T_{g}$ with the degree-of-cure can be modelled with the DiBenedetto equation

(Step 4a) Several cure shrinkage measurement methods have been developed, such as capillarity dilatometry (Hill, Muzumar, Lee (1995)), a shadow Moire method (Daniel, Wang, Karalekas, Gotro (1990)), Dynamic Mechanical Analysis (DMA) and Thermo Mechanical Analysis (TMA) (Yu, Mhaisalkar, Wong (2005), Schoch, Panackal, Franck (2004)), LVDT transducers and optical sensors (Watts, Cash (1991), Thomas, Bur (1999)), gravimetric methods (Li et al (2004)) or in-house multifunctional benches (Nawab, Casari, Boyard, Jacquemin (2013), Boyard et al (2003)). A modified rheology test can also be used to measure the resin cure shrinkage (Haider, Hubert, Lessard (2007)). The measured volumetric cure shrinkage can be modelled as a function of the degree-of-cure obtained from DSC experimental data.

(Step 4b) Thermal Mechanical Analysis (TMA) is the most common method used to measure the coefficient of thermal expansion of the neat resin (Ruiz, Trochu (2005)). This method measures the through thickness expansion of a sample with temperature. The influence of the curing temperature and the degree-of-cure can be investigated using fully and partially cured resin samples.

(Step 4c) Tracing the evolution of the elastic modulus with the degree-of-cure is not simple, as the resin sees different physical states while curing. Dynamic mechanical tests in three point bending mode can be used for this purpose on non-cured adhesive (Curiel, Fernlund (2006)), or pre-cured resin.

Table 3 presents the thermochemical properties of two common OOA resins: MTM45-1 and 5320 (Kratz et al (2013)).

\section{Cure kinetics model}

\begin{tabular}{|l|l|l|}
\hline \multicolumn{2}{|l|}{$\frac{d \alpha}{d t}=K_{1} \alpha^{m 1}(1-\alpha)^{n 1}+\frac{K_{2} \alpha^{m 2}+(1-\alpha)^{n 2}}{1+\exp \left(D\left(\alpha-\left(\alpha_{C 0}+\alpha_{C T}\right)\right)\right)}$ where $K_{1}=A_{1} \exp \left(\frac{-E_{A 1}}{R T}\right) K_{2}=A_{2} \exp \left(\frac{-E_{A 2}}{R T}\right)$} \\
\hline Parameter & MTM45-1 & $\mathbf{5 3 2 0}$ \\
\hline$A_{1}\left(\mathrm{~s}^{-1}\right)$ & $2.53 \times 10^{4}$ & $8.23 \times 10^{7}$ \\
\hline
\end{tabular}




\begin{tabular}{|c|c|c|}
\hline$E_{\mathrm{A} 1}(\mathrm{~J} / \mathrm{mol})$ & 60628 & 82375 \\
\hline$m_{1}$ & 0.55 & 0.75 \\
\hline$n_{1}$ & 21.11 & 12.46 \\
\hline$A_{2}\left(\mathrm{~s}^{-1}\right)$ & $4.84 \times 10^{4}$ & $1.04 \times 10^{5}$ \\
\hline$E_{\mathrm{A} 2}(\mathrm{~J} / \mathrm{mol})$ & 61752 & 62355 \\
\hline$m_{2}$ & 0.80 & 0.90 \\
\hline$n_{2}$ & 1.18 & 2.07 \\
\hline$D$ & 44.3 & 40.4 \\
\hline$\alpha_{C 0}$ & -1.4 & -1.12 \\
\hline$\alpha_{C T}\left(\mathrm{~K}^{-1}\right)$ & $5.33 \times 10^{-3}$ & $4.53 \times 10^{-3}$ \\
\hline \multicolumn{3}{|c|}{ Glass transition temperature model } \\
\hline \multicolumn{3}{|c|}{$\frac{T_{g}-T_{g 0}}{T_{g \infty}-T_{g 0}}=\frac{\lambda \alpha}{1-(1-\lambda) \alpha}$} \\
\hline Parameter & MTM45-1 & 5320 \\
\hline$T_{g 0}\left({ }^{\circ} \mathrm{C}\right)$ & -8.6 & -8.4 \\
\hline$T_{g} \infty\left({ }^{\circ} \mathrm{C}\right)$ & 210 & 212 \\
\hline$\lambda$ & 0.83 & 0.66 \\
\hline \multicolumn{3}{|c|}{ Viscosity model } \\
\hline \multicolumn{3}{|c|}{$\mu=\mu_{1}+\mu_{2}\left(\frac{\alpha_{g e l}}{\alpha_{g e l}-\alpha}\right)^{A+B \alpha+C \alpha^{2}} \mu_{i}=A_{\mu i} \exp \left(\frac{E_{\mu i}}{R T}\right), i=1,2$} \\
\hline Parameter & MTM45-1 & 5320 \\
\hline$A_{\mu 1}(\mathrm{~Pa} \cdot \mathrm{s})$ & $1.8 \times 10^{-5}$ & $8.0 \times 10^{-13}$ \\
\hline$E_{\mu 1}(\mathrm{~J} / \mathrm{mol})$ & 42050 & 93931 \\
\hline$A_{\mu 2}(\mathrm{~Pa} \cdot \mathrm{s})$ & $6.9 \times 10^{-13}$ & $2.9 \times 10^{-11}$ \\
\hline$E_{\mu 2}(\mathrm{~J} / \mathrm{mol})$ & 95710 & 83400 \\
\hline$\alpha_{g e l}$ & 0.40 & 0.48 \\
\hline
\end{tabular}




\begin{tabular}{|l|l|l|}
\hline$A$ & 6.3 & 3.2 \\
\hline$B$ & -9.9 & 12.7 \\
\hline$C$ & 9.4 & -29.6 \\
\hline
\end{tabular}

\subsection{Degree of Impregnation}

Degree of impregnation (UD) has been defined as the percent of interstitial volume filled with resin. For a unidirectional fibre architecture, this can be visualized quite simply in Figure 7. Figure 7 a) shows a prepreg where the fibres are entirely dry, thus the DOI is $0 \%$. Figure 7 b) and c) show prepreg where the exactly half and all of the fibres are surrounded by resin, respectively, thus the DOI for these images is $50 \%$ and $100 \%$, respectively.
a) $\mathrm{DOI}=0 \%$
b) $\mathrm{DOI}=50 \%$
c) $\mathrm{DOI}=100 \%$
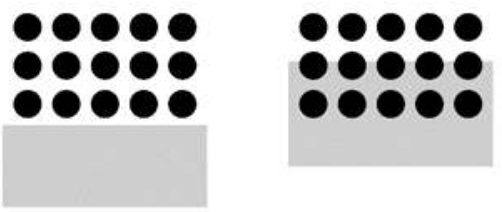
:::::

Figure 7 Schematic demonstrating the degree of impregnation for a unidirectional prepreg where the interstitial volume is a) $0 \%$, b) $50 \%$, and c) $100 \%$ filled with resin.

For unidirectional fibre prepreg, the degree of impregnation is the ratio of volume of impregnated fibres to the total volume of the prepreg (Figure 8). If the analysis is performed from micrographs or micro-CT slices, areas found from cross sectional images are used. It is assumed that using many cross sections will be representative of the entire volume of the prepreg. For unidirectional prepreg, the degree of impregnation is defined by:

$D O I_{U D}=1-\frac{A_{\text {dry fibre }}}{A_{\text {total }}}$

where $A_{d r y}$ fibre is the area of dry fibre regions, $A_{\text {total }}$ is the sum of the area of fibres surrounded by resin, the resin rich area and the dry fibres area.

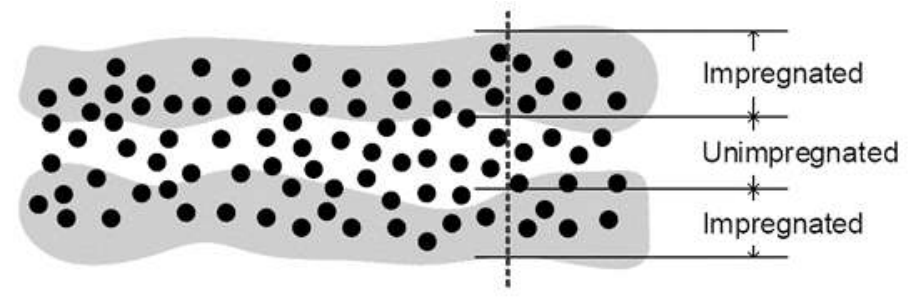

Figure 8 Definition of degree of impregnation for UD prepreg with a small region of prepreg highlighted for clarity. 
For fabric prepregs, the degree of impregnation is again measured using visible dry fibre area. As with the UD prepreg, it is difficult to measure the actual tow size because methods to measure the uncompacted size would distort the tow shape, causing error. As a result, the degree of impregnation measured is a relative value (Figure 9). Thus, the fabric prepreg degree of impregnation is defined as:

$D O I_{F A B R I C}=1-\sqrt{\frac{A_{i, \text { processed }}}{\bar{A}_{\text {unprocessed }}}}$

where $A_{i, p r o c e s s e d}$ is the measured dry region for the given tow and $\bar{A}_{\text {unprocessed }}=$ $\sum_{i=1}^{n} A_{i, \text { unporcessed }} / n$ is the average dry region measured for the unprocessed tows defined in Figure 9. In this sense, the degree of impregnation is relative and has a range from 0 for the unprocessed tows to 1 for the fully impregnated tows. A degree of impregnation value is found for each tow and an average value is taken for the specimen. For cases when the measured dry area is less than the average initial dry area, the degree of impregnation is set to 0 . This procedure is done for $n=10$ to 30 tows per specimen.

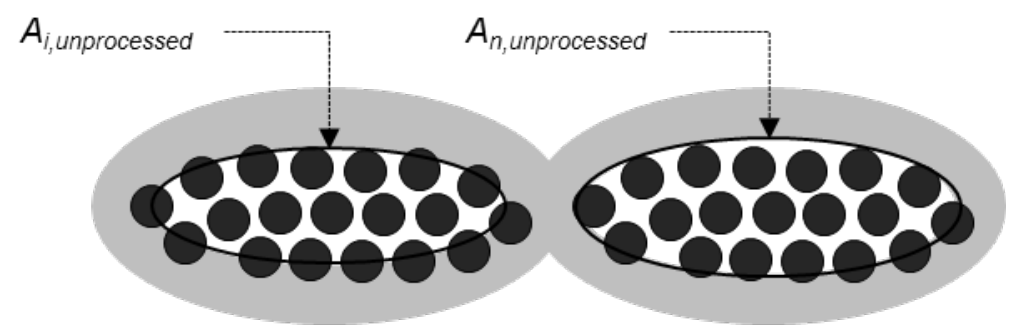

A) Unprocessed

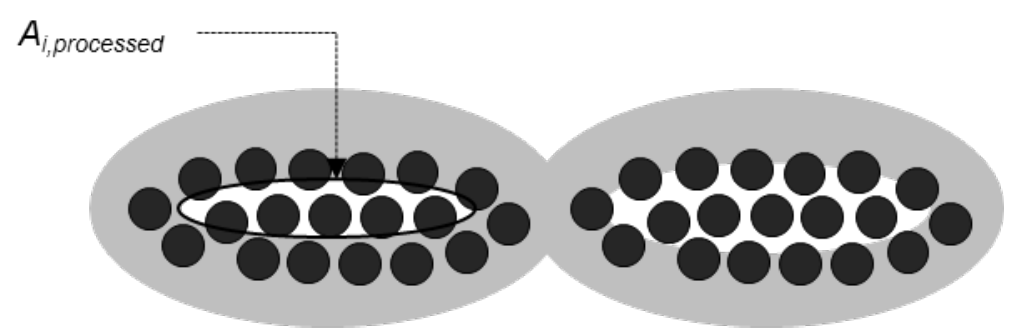

B) Processed

Figure 9: Parameters used to calculate tow degree of impregnation $A_{i, p r o c e s s e d}$.

Many methods to quantify impregnation involve specimen imaging like manually counting dry and wetted fibres from optical or scanning electron microscopy images (Peltonen, Järvelä (1992), Ye, Klinkmuller, Friedrich (1992), Vallittu (1995)). Micro-CT was used to quantify degree of impregnation by measuring the visible dry tow area of specimens throughout a processing cycle (Centea, Hubert (2011)). Besides X-rays, attenuation of beta-rays can also be used to accurately measure resin content (Huang et al (1998), Huang, Sun, Liu (2003)). Near infrared spectroscopy has also been used to measure different parameters of prepreg, including the resin content (Li, Huang, Liu, Chen (2005), Li, et al (2006)). Ultrasonic techniques were used to qualitatively measure the through thickness flow of resin into a single layer of dry fibre during the resin film 
infusion process (Jiang, Huang (2008), Thomas, Bongiovanni, Nutt (2008)) and woven carbon fibre reinforced polymer composites (Thomas, Nutt (2009)). Finally, infrared thermography was used to measure prepreg thermal diffusivity that correlate well to the degree of impregnation values obtained through micro-CT (Palardy-Sim, Hubert (2015)).

Figure $10 \mathrm{~A}$ ) illustrates the steps to quantify impregnation with images obtained from micro-CT scans of an unidirectional fibre prepreg. Grayscale thresholding is used to convert grayscale images to black and white by picking a specific grey value that acts as the cut-off, or threshold. Pixels with intensity greater than the threshold will be given an intensity of 1 (white pixels) and pixels below will be given an intensity of 0 (black). Thresholding is first used to isolate the prepreg from the background. Subsequently, the white pixel regions are dilated, increasing their size, before applying a filling function which fills the internal dry regions. Next the image is eroded, to reduce the outline to match the initial prepreg cross-section. Using this method, it is possible to isolate the prepreg from the polystyrene foam clamps used to hold the specimen. Next, the internal dry regions are measured by another threshold. In order to calculate degree of impregnation, the cross section is split up into many pixel columns with impregnated pixels having an intensity value of 1 and non-impregnated pixels having an intensity value of 0 . As such, it is possible to measure a degree of impregnation value for every pixel column of the cross section. Finally, average values can be calculated for the entire specimen - ignoring the left and right ends of the images to remove edge effects such as separation of the impregnated regions of the prepreg caused by specimen preparation. Furthermore, the value taken for each pixel column within an image is used to create degree of impregnation maps which provide detailed information about the variation in degree of impregnation over the entire area of the specimen. Figure $10 \mathrm{~B}$ ) illustrates the analysis of a 8HS fabric laminate. Starting from the cross sectional images (Figure $10 \mathrm{~B}$ a)), individual tows are selected b) and an ellipse is drawn to roughly outline the tow c). The area within the ellipse is isolated d) and using greyscale thresholding the image is converted to black and white e). Otsu's method is used in order to determine a greyscale threshold value that minimizes intraclass variance. Finally, the region of the tow is isolated by filtering, smoothing, and selection based on pixel area f). This method has a good ability to select and measure dry tow regions as is shown in g).

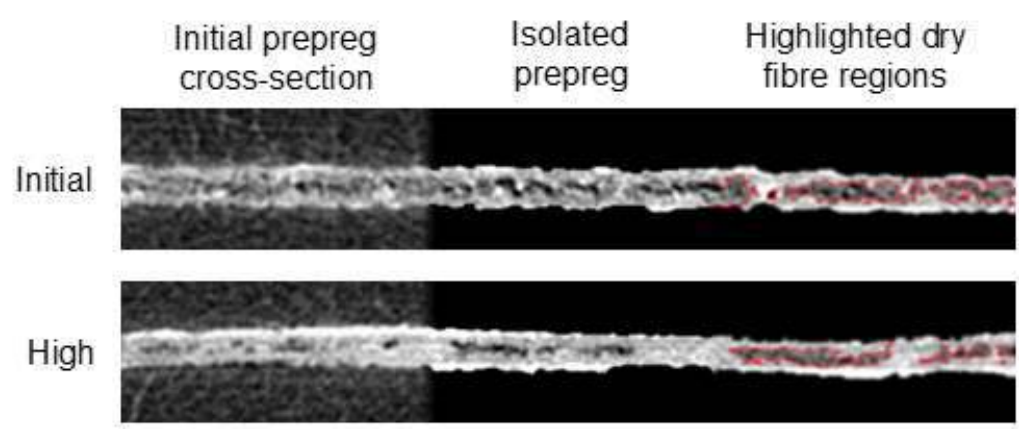




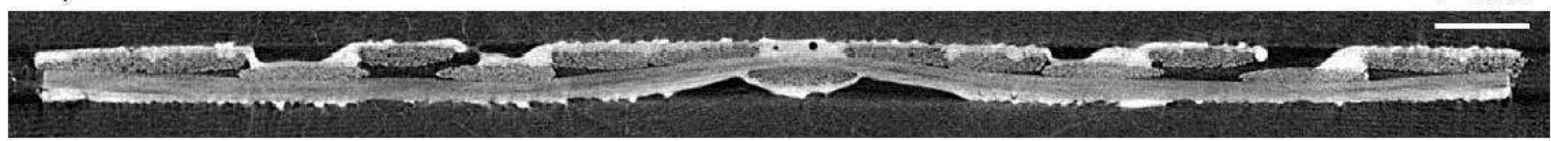

b)

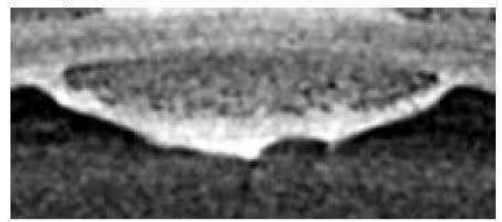

e)

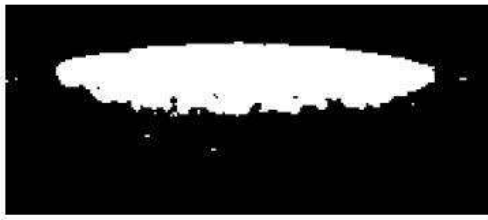

c)

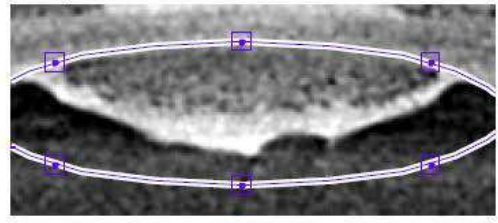

f)

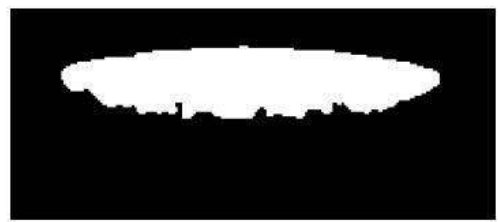

d)

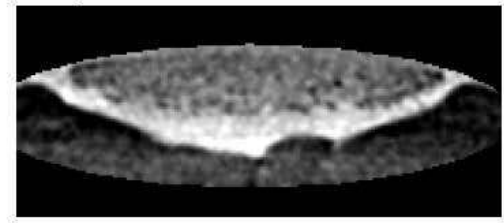

g)

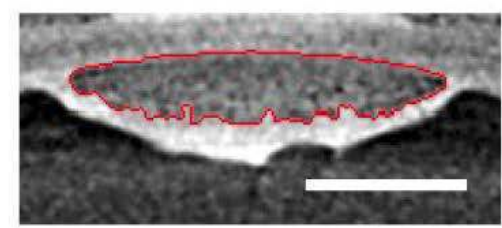

$500 \mu \mathrm{m}$

Figure 10 Image post-processing used to measure degree of impregnation of A) UD prepreg and B) $8 \mathrm{HS}$ fabric prepreg.

\subsection{Permeability}

The material property that describes fluid flow through a porous medium is permeability (Bear (1972)). The apparent fluid velocity, $v$, is described by Darcy's law:

$$
\frac{\overline{\bar{K}}}{\mu} \nabla P=-v
$$

where $\mathrm{K}$ is the permeability tensor, $\mu$ is the fluid viscosity, and $\mathrm{P}$ is the fluid pressure. The intrinsic permeability of a Darcy material is determined solely by the void spaces created by the solid matrix, and is independent of both the fluid properties and flow mechanisms (Dullien (1979)). In the case of prepreg materials, fibres and resin are considered the solid phase, therefore air permeability measurements do not represent the intrinsic permeability of the fibrebed, but rather estimate the gas flow capacity of a multi-phase material. Using a constitutive law for air pressure, such as the ideal gas law, the air permeability can then be used to predict vacuum hold times to evacuate air from prepreg lay-ups (Kratz, Hubert (2013), Tavares, Michaud, Manson (2009), Cender, Simacek, Davis, Advani (2016), Cender, Simacek, Advani (2013)). A similar approach is employed in liquid composite moulding processes, where permeability is used with resin incompressibility to estimate flow front position (Advani, Sozer (2011)).

The permeability of prepreg materials can be calculated from experiments where a constant gas flowrate is applied in a single direction of the sample and the pressure drop across this length is measured. Conversely, adding reservoirs of calibrated volumes and measuring the time for the pressure in each volume to equilibrate can also be used to measure the permeability. The in-plane air permeability is typically three to four orders of magnitude higher than the transverse air 
permeability because of the partially impregnated microstructure shown in Figure 1; the partially saturated tows creates a planar void space for air to flow and as a result the in-plane permeability ( $\mathrm{K}_{\mathrm{xx}}$ and $\mathrm{K}_{\mathrm{yy}}$ are roughly equivalent in woven or quasi-isotropic unidirectional layups) can be up to several orders of magnitudes higher than the through-thickness $\left(\mathrm{K}_{\mathrm{zz}}\right)$ permeability (Figure 11). The through-thickness air permeability can be improved by spiking the layers individually or the entire layup using a porcupine roller (Tavares et al. (2010B)). Although the through-thickness permeability is much lower than the in-plane permeability, the aspect ratio of most laminates is such that gas evacuation may be faster, as discussed in Section 4.2.

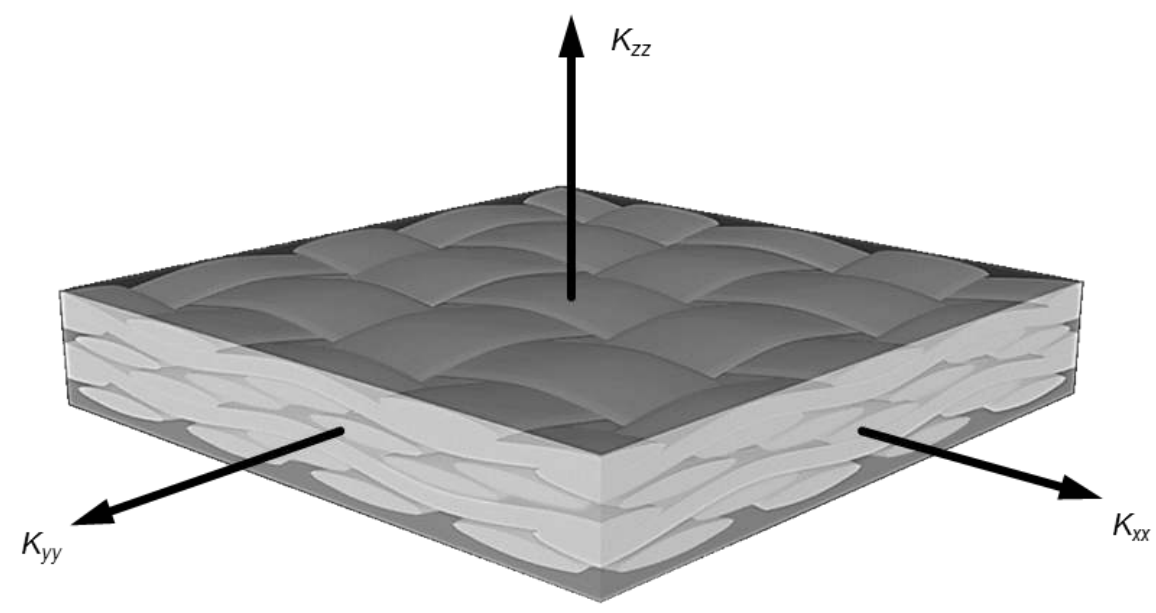

Figure $113 \mathrm{D}$ view of the laminate showing the permeability in the principal directions.

Table 4 presents typical prepreg air permeability values for common OOA prepreg materials at room temperature.

Table 4. OOA prepreg air permeability $\left(\right.$ in $\left.\mathrm{m}^{2}\right)$ at room temperature.

\begin{tabular}{|l|l|l|l|}
\hline Material & $\mathbf{K}_{\mathbf{x x}} *$ & $\mathbf{K}_{\mathbf{y y}}$ & $\mathbf{K}_{\mathbf{z z}}$ \\
\hline Unidirectional & $1.0 \times 10^{-15}-1.0 \times 10^{-12}-$ & $1.0 \times 10^{-19}-5.0 \times 10^{-18}$ & $1.0 \times 10^{-19}-5.0 \times 10^{-18}$ \\
\hline Plain weave & $3.8 \times 10^{-15}-1.1 \times 10^{-14}$ & $3.8 \times 10^{-15}-1.1 \times 10^{-14}$ & $5.0 \times 10^{-17}-7.8 \times 10^{-17}$ \\
\hline 5HS Satin & $6.0 \times 10^{-15}-1.1 \times 10^{-14}$ & $6.0 \times 10^{-15}-1.1 \times 10^{-14}$ & $7.0 \times 10^{-18}-2.5 \times 10^{-17}$ \\
\hline
\end{tabular}

* fibre or weft direction

Several parameters can significantly affect OOA prepreg air permeability. Table 5 lists qualitative effect of the most important factors on air permeability (Tavares, Michaud, Manson (2009), Kratz, Hubert (2013), Louis, Hsiao, Fernlund (2010), Centea et al (2012)). The increase in ply thickness can lead to a significant reduction of transverse permeability. The introduction of air paths through the prepreg thickness by spiking or adding aligned gaps can significantly improve the transverse permeability. This approach however causes a reduction of mechanical performance as it creates fibre path discontinuities in the material. Staggered gaps can reduce the negative impact on 
mechanical properties but is not as efficient in increasing the transverse permeability. Ply drop-off can cause a reduction in in-plane permeability as edge air evacuation pathways are not connected to the edge breathing system. The application of vacuum during the debulking phase causes a small reduction in the prepreg permeability as some of the air paths are closed by the prepreg compaction. Temperature can also affect permeability as the resin soften which allow air flow to increase and consequently increase the prepreg permeability. This effect is more dominant at the minimum resin viscosity point and is reversed as the resin impregnates the dry fibre bundles.

Table 5 Effect of material and process parameters on prepreg air permeability.

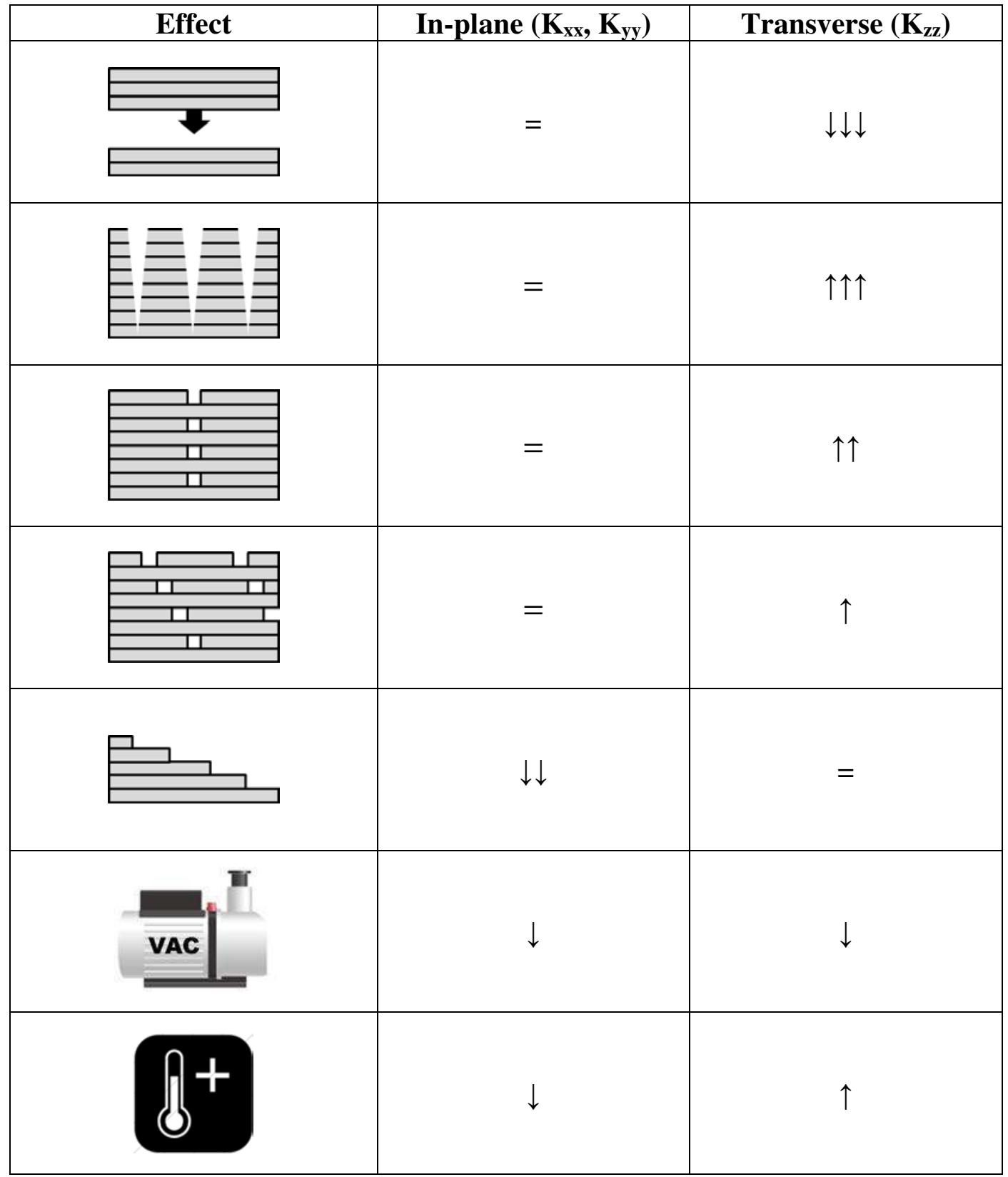




\subsection{Bulk Factor}

The prepreg bulk factor represents the change in material thickness during the curing phase. The change of thickness is attributed to the compaction of voids and to the fibre tow impregnation by the resin. Depending on the prepreg initial degree of impregnation and fibre architecture, OOA prepregs have a range of bulk factor. The bulk factor $(\beta)$ is defined as follow:

$\beta=\frac{t_{i}}{t_{f}}$

where $t_{f}$ and $t_{i}$ are the final (cured) and initial (uncured) prepreg thickness respectively. It is a common practice to consider the initial prepreg thickness as the thickness after the debulking phase. The thickness can be measured with calipers, dial gauges and LVDTs. The bulk factor can be affected by the processing conditions like vacuum level, atmospheric pressure, temperature cycle and prepreg out-time. Table 6 presents typical bulk factor values for common OOA prepreg materials processed in ideal conditions.

Table 6. OOA prepreg bulk factors

\begin{tabular}{|l|l|}
\hline Material & Bulk factor \\
\hline Unidirectional & $1.08-1.17$ \\
\hline Plain weave & $1.15-1.27$ \\
\hline 5HS Satin & $1.16-1.38$ \\
\hline 8HS Satin & $1.20-1.40$ \\
\hline
\end{tabular}

\section{Processing Infrastructure}

\subsection{Heating and Vacuum Sources}

The capacity to manufacture high-quality parts using OOA prepreg processing eliminates the need for a pressurized vessel. Hence, infrastructure selection consists of choosing appropriate heating and vacuum sources.

Heat is typically supplied by a convection oven. During oven cure, the laminate and tool are heat sinks, while the external environment is a heat source. Oven selection depends on several factors, including thermal characteristics, size requirements, and cost. Generally, any oven capable of achieving the required dwell temperature and ramp rates (and possessing a pass-through for a vacuum line) is suitable for OOA cure. However, note that while ovens are less expensive than autoclaves, their heat transfer performance is lower as well. Consequently, processing trials should be used to measure the heat-up and cool-down rates of the actual part, as well as the location of magnitude of any through-thickness or in-plane thermal gradients. Convection ovens are broadly applicable to OOA prepreg cure. 
Heat can also be supplied by heated tools and/or blankets, enabling reductions in the size and footprint of curing infrastructure. Heated tools use electrical or fluid-based systems to impart heat directly from the tool-side surface. Conversely, heating blankets are placed on the bag side, but must account for heat losses into the tool. In both cases, the use of conductive (rather than convective) heat transfer allows faster temperature ramping and decreases cure time. Moreover, heated tools and blankets allow local control of temperature, and can be used to mitigate unwanted thermal gradients (or, conversely, take advantage of spatial variations in temperature). The viability of heated tool and blanket cure has been demonstrated in the literature (for example, Payette et al (2015)). However, one-sided heating schemes are vulnerable to tool-side or bag-side heat losses, and successful cure requires thermal analysis and accurate temperature control. Heating tools are theoretically well-suited to applications requiring fast heat-up and cool-down, to parts with large thickness variations (and local exotherms), and to manufacturing locations in which space is limited. Conversely, heated blankets are useful for situations in which infrastructure is limited, such as in-field repairs, or for spot heating. Finally, heated tools and blankets can be used during oven cure to impart additional heat or resolve non-uniform temperature distributions.

An interesting (though still niche) development in OOA prepregs involves resin systems capable of self-driven cure. This non-autoclave/non-oven (NONA) (Dietsch (2014)) approach uses the heat released by the exothermic cure reaction to control the rate of reaction, and theoretically requires no external heat application. However, part design, tool geometry, and resin chemistry must be optimized in unison to avoid runaway exotherms and material degradation, or incomplete cure.

Finally, OOA prepregs can be cured using numerous traditional methods, including autoclave cure and press forming. However, such approaches do not leverage the partial impregnation of the prepreg, and sacrifice the potential benefits of OOA cure.

Table 7 Heating methods and their advantages $(\Uparrow)$, disadvantages $(\Downarrow)$, and potential use cases.

\begin{tabular}{|c|c|c|}
\hline Method & Advantages and Disadvantages & Potential Use Cases \\
\hline Oven & $\begin{array}{l}\Uparrow \text { Broad applicability } \\
\Downarrow \text { Slow heating and cooling } \\
\Downarrow \text { Thermal gradients }\end{array}$ & All \\
\hline $\begin{array}{l}\text { Heated } \\
\text { tool }\end{array}$ & $\begin{array}{l}\Uparrow \text { Rapid heating and cooling } \\
\Uparrow \text { Multi-zone thermal control } \\
\Downarrow \text { Complex, potentially expensive }\end{array}$ & \multirow{2}{*}{$\begin{array}{l}\text { - Small or medium-sized } \\
\text { parts } \\
\text { - No oven is available } \\
\text { - } \\
\text { - Heat transfer from } \\
\text { oven or autoclave is } \\
\text { insufficient } \\
\text { - Local control of heat } \\
\text { transfer is desired }\end{array}$} \\
\hline $\begin{array}{l}\text { Heated } \\
\text { blanket }\end{array}$ & $\begin{array}{l}\Uparrow \text { Rapid heating and cooling } \\
\Uparrow \text { Multi-zone thermal control } \\
\Uparrow \text { Low cost } \\
\Downarrow \text { Less reliable or consistent than oven or heated tool }\end{array}$ & \\
\hline
\end{tabular}

The selection of a vacuum source for OOA cure is simple, since the sole major requirement is to maintain a constant bag pressure of $<5 \mathrm{kPa}$ (or vacuum level of $>28.5 \mathrm{in} \mathrm{Hg}$ ). Hence, the selection of a specific pump model will often depend on case-specific factors such as required flowrate (which governs the number of parts that can be cured in parallel) and cost. 


\subsection{Tooling}

OOA prepregs can be cured on any autoclave-capable tool. However, OOA resins enable the use of low-temperature, low-cost tooling materials because they can develop sufficient green strength at $\leq 130^{\circ} \mathrm{C}$, prior to a free-standing post-cure. Moreover, OOA prepregs are potentially well-suited to curing on integrally heated tools, as discussed in the previous section. Generally, the thermal processing window of OOA prepregs leads to a wider tool selection space, in which composite, metallic, polymeric or wood materials can be selected based on thermal expansion, durability, cost, availability, or other factors.

\subsection{Process Diagnostics}

Without high pressure, OOA prepreg processing is sensitive to sub-optimal material properties and curing conditions. As a result, successful production requires careful process selection and accurate control of material state, temperature, and vacuum quality before and during cure. Recently, research has demonstrated the use of process diagnostics that enable in-situ monitoring of relevant data and real-time control over temperature and pressure. Examples of input signals include temperature, pressure, fluid flow, and dielectric properties. A simple schematic with examples of in-situ monitoring is shown in Figure 12.

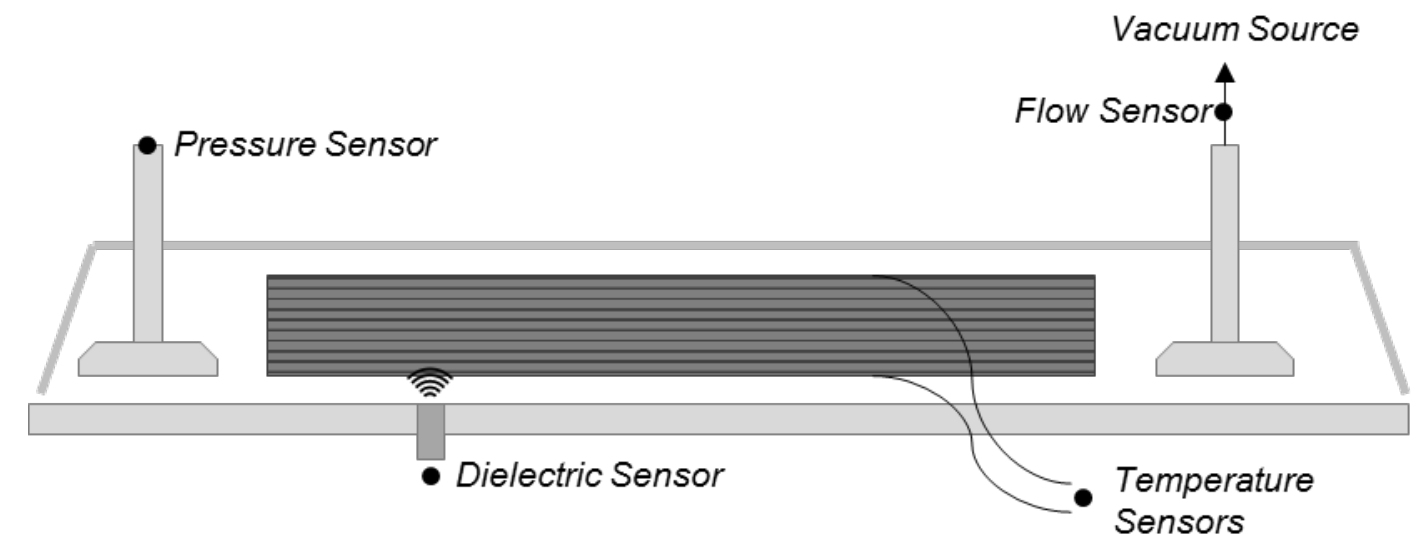

Figure 12 Schematic of tool plate with in-situ process diagnostics.

Temperature sensors can track spatial and time variations in thermal conditions. This data can, in turn, be combined with analytical models to compute the evolving thermochemical and physical properties of the resin (e.g. cure kinetics, viscosity and glass transition temperature), as well as estimate more complex physical phenomena, such as resin flow and defect formation. Temperature sensors can be integrated into the heating environment, embedded within the tool, or inserted directly within the prepreg part.

Pressure transducers can be used to monitor and record gas pressure within a vacuum bag. Vacuum quality is closely correlated with the microstructural quality of cured parts, with literature showing that even for lab-scale parts, $10-20 \%$ reductions are sufficient to induce bulk and surface porosity (Centea, Hubert (2014), Hamill, Centea, Nutt (2015)). Ideally the pressure sensor should be connected to the bag using a stand-alone vacuum port (rather than located in series with the vacuum pump), and placed as close as possible to the point of interest. Measurements can be made by a 
sensor placed in series between the bag and vacuum pump. However, vacuum levels detected in this configuration can differ from those experienced by the part.

Flow sensing can be used to detect and locate vacuum bagging issues. The rate of gas flow through multiple vacuum valves distributed throughout a vacuum bag can be recorded and used to triangulate the likely location of a leak. For example, a commercially available leak detection and triangulation system has been developed by Convergent Manufacturing Technologies (Vancouver, Canada). In theory, the rate of out-flowing gas can also be used to determine the extent of air evacuation from a laminate; however, in practice, low flow rates preclude accurate sensing.

Dielectric analysis (DEA) can be used to monitor the evolution of resin properties during OOA manufacturing. Prior to cure, the resin conductivity (measured at a specific frequency) can be used to accurately estimate prepreg out-time, a major cause of flow-induced porosity, and identify material conditions that prevent successful cure (Kim, Centea, Nutt (2014a)). During cure, the measured maxima of the imaginary impedance signal can be converted into degree of cure, and therefore used to predict other resin properties and/or validate model predictions (Kim, Centea, Nutt (2014a), Kim, Centea, Nutt (2014b)). Dielectric sensors in the form of flat, interdigital electrodes can be integrated within the tool surface or embedded between laminate plies, allowing local and instantaneous data collection.

These process diagnostics, summarized in Table 8, can be used for real-time process control. Resin cure kinetics and viscosity data derived from temperature sensors, dielectric sensors, and predictive models can be used to modulate heating (or cooling) rates and, in the case of multi-zone heated tools or heated blankets, manage thermal gradients. Similarly, pressure and flow data can be employed to vary pump power or, at minimum, provide alerts about leaks. Traditionally, autoclave cure discouraged the addition of sophisticated transducers by requiring pressure-sealed pass-through for all hardware. In contrast, OOA processing both enables and benefits from instrumented curing environments.

Table 8 In-situ process diagnostics.

\begin{tabular}{|l|l|l|l|}
\hline Method & Data & Sensor Location & Cost/Complexity \\
\hline Temperature & $\begin{array}{l}\text {-Temperature vs. time and } \\
\text { location } \\
\text {-Resin properties (if models } \\
\text { available) }\end{array}$ & $\begin{array}{l}\text {-Part } \\
\text {-Tool } \\
\text {-Bag }\end{array}$ & Low \\
\hline Pressure & $\begin{array}{l}\text {-Bag pressure vs. time } \\
\text {-Leak existence }\end{array}$ & $\begin{array}{l}\text {-Valve (parallel) } \\
\text {-Vacuum system (series) }\end{array}$ & Low \\
\hline Flow & $\begin{array}{l}\text {-Leak existence and location } \\
\text {-Air evacuation rate }\end{array}$ & -Vacuum system (series) & Medium \\
\hline Dielectric & $\begin{array}{l}\text {-Resin out-time } \\
\text {-Resin properties (if } \\
\text { correlation available) }\end{array}$ & $\begin{array}{l}\text {-Tool } \\
\text {-Part }\end{array}$ & High \\
\hline
\end{tabular}




\section{Process Design}

\subsection{Vacuum Bag and Consumables}

Out-of-autoclave prepreg processing relies on vacuum-induced laminate consolidation. Thus, the use of an effective vacuum bagging arrangement is critical to fabricating low defect parts.

The design of the vacuum bag and consumable arrangement should ideally:

1. Allow the vacuum pump to reduce the bag pressure to a sufficiently low level by creating a tight, leak-free seal between the bag and external environment

2. Transfer heat from the external environment to the laminate

3. Provide sufficient compaction pressure over the entire surface of the part

4. Foster air evacuation from the part while limiting resin bleed

In principle, vacuum bags used for OOA processing are similar to those employed for autoclave cure. However, successful VBO cure relies on a few particular arrangements.

The nominal list of consumables used to create the vacuum bag, along with their function, is listed in Table 9. Moreover, a basic vacuum bag is shown schematically in Figure 13. First, a liquid release agent or solid release film is used to prevent adhesive bonding between the tool and toolside prepreg ply. The use of liquid release is preferable for tools with complex curvatures, for which cutting and draping a solid film is challenging. However, tests have shown that thin fluoropolymer release films can lead to lower tool-side surface porosity and a more uniform, glossier surface finish (Hamill, Centea, Nutt (2015)).

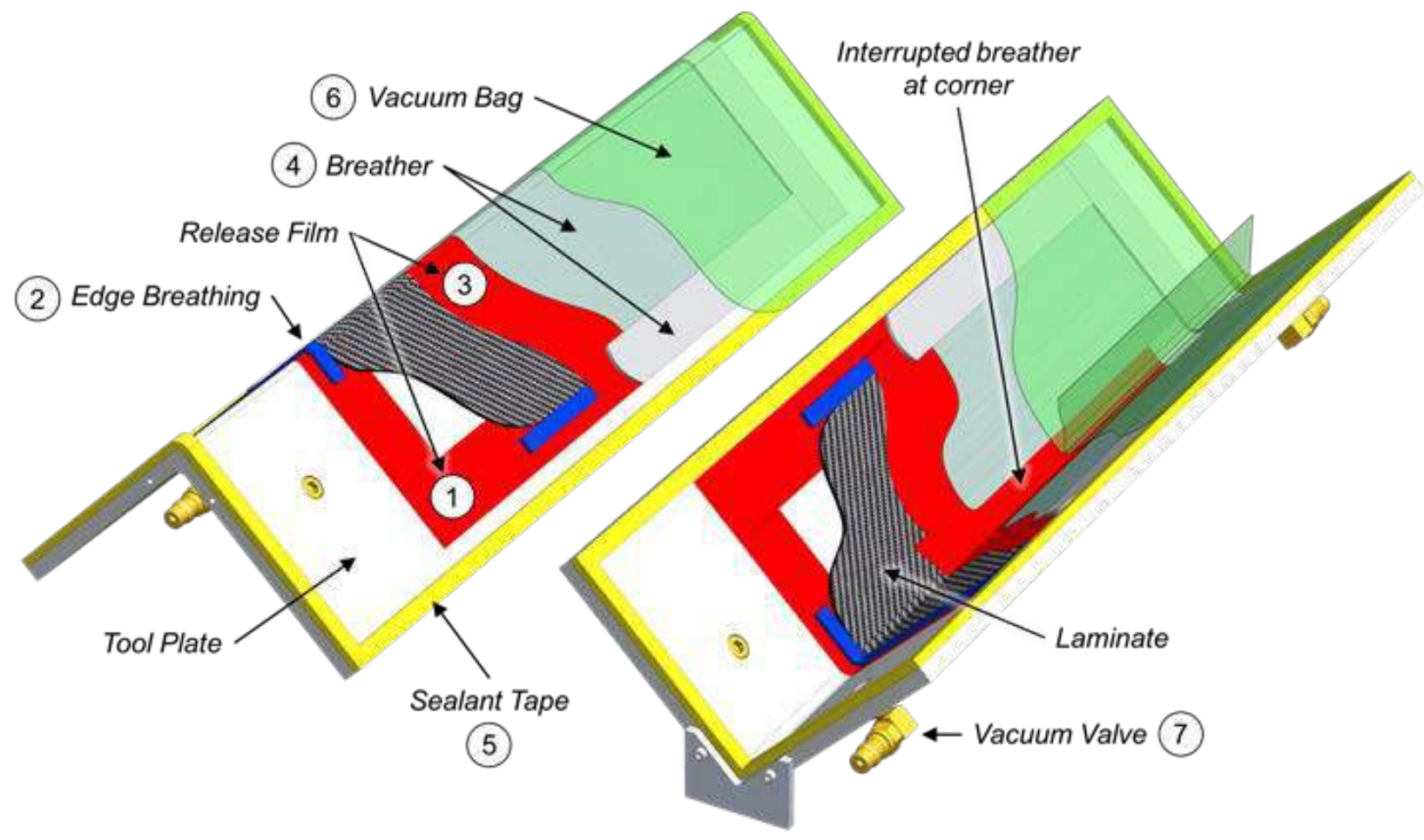


Figure 13 Schematic of vacuum bagging assembly, including tool, laminate, edge breathing dams, release films, breather, edge breathing, and vacuum port. The breather at corner regions is removed to enhance the compaction applied to the laminate by the vacuum bag.

Next, once the part is positioned on the tool, edge breathing dams are placed around the laminate perimeter. These dams can consist of any material that allows gas transport while restricting laminate movement, resin bleed, and the "pinching" (or over-compaction) of ply terminations by the vacuum bag. In practice, they are often formed by wrapping fibreglass boat cloth around sealant tape or cork. For most OOA prepregs, edge breathing dams are critical for successful cure, since in-plane air evacuation is the primary mechanism for preventing bulk porosity. For best results:

- The dam height should be approximately equal to the initial laminate height.

- The dams should be in contact with every ply terminating at the laminate perimeter.

- Edge breathing dams should be located around the entire perimeter, including internal cutouts, to minimize the in-plane distance that any gas molecule must travel.

Typically, the bag-side surface of the laminate is covered by a permeable consumable that allows air evacuation in the through-thickness direction while limiting resin bleed and contamination of the laminate by other consumables or foreign objects. Often, the bag-side release film consists of a perforated release film, which features a regular grid of perforations. However, other materials, including peel plies, can be used to impart specific surface textures.

Finally, the vacuum bag is completed by adding breather cloth, one or more vacuum valves, and the bagging film, and fixing the bag to the tool using sealant tape. At this stage, the consumables should be arranged so as to prevent bridging at concave corners, wrinkles in flat or convex regions, or other situations that can limit compaction or impart unwanted surface blemishes. Such considerations are similar to those associated with autoclave processing. However, the limited compaction pressure available during OOA cure renders them particularly important for this manufacturing route. For example, one potential method to limit wrinkle formation in concave corners is to interrupt the breather in the corner area (Figure 13).

The vacuum bag, once complete, should be tested for leaks by disconnecting the vacuum pump and monitoring the bag pressure. The typical leak rate used for bag acceptance in industrial practice is $\leq 0.7 \mathrm{kPa} / \mathrm{min}(1$ in $\mathrm{Hg}$ per $5 \mathrm{~min})$.

Table 9 List of consumables in Figure 13, with functions and notes.

\begin{tabular}{|l|l|l|}
\hline Consumable & Function & Notes \\
\hline Release Agent & $\begin{array}{l}\text { Prevent adhesive bonding between } \\
\text { tool and ply surfaces, particularly } \\
\text { for complex-shaped tools }\end{array}$ & $\begin{array}{l}\text { Liquid release agents may be replaced } \\
\text { by release film to improve tool-side } \\
\text { surface finish }\end{array}$ \\
\hline $\begin{array}{l}\text { (1) Release } \\
\text { Silm (Tool- }\end{array}$ & $\begin{array}{l}\text { Prevent adhesive bonding between } \\
\text { tool and ply surfaces, particularly } \\
\text { for complex-shaped tools }\end{array}$ & $\begin{array}{l}\text { The tool-side release film should be } \\
\text { non-perforated. }\end{array}$ \\
\hline
\end{tabular}




\begin{tabular}{|l|l|l|}
\hline $\begin{array}{l}\text { (2) Edge } \\
\text { Breathing } \\
\text { Dams }\end{array}$ & $\begin{array}{l}\text { Allow air transport at the laminate } \\
\text { perimeter while restraining } \\
\text { laminate movement, reducing resin } \\
\text { bleed, and preventing "pinching". }\end{array}$ & $\begin{array}{l}\text { Edge breathing dams should be the } \\
\text { same height as laminate, in contact } \\
\text { with every ply, and located around the } \\
\text { entire laminate }\end{array}$ \\
\hline $\begin{array}{l}\text { (3) Release } \\
\text { Silm (Bag- }\end{array}$ & $\begin{array}{l}\text { Separate the bag-side laminate } \\
\text { surface from other consumables. }\end{array}$ & $\begin{array}{l}\text { The tool-side release film may be } \\
\text { perforated in order to allow through- } \\
\text { thickness gas transport from the } \\
\text { laminate surface, or replaced by a } \\
\text { different permeable consumable (e.g. } \\
\text { peel ply) }\end{array}$ \\
\hline $\begin{array}{l}\text { (4) Breather } \\
\text { Tape }\end{array}$ & $\begin{array}{l}\text { Ensure a uniform vacuum pressure } \\
\text { distribution throughout the bag }\end{array}$ & $\begin{array}{l}\text { Breather may be removed from } \\
\text { concave corner regions to improve } \\
\text { corner compaction. }\end{array}$ \\
\hline $\begin{array}{l}\text { (6) Vacuum } \\
\text { Bag }\end{array}$ & $\begin{array}{l}\text { Form the vacuum bag by separating } \\
\text { the laminate and consumables from } \\
\text { the outside environment, and apply } \\
\text { compaction to the part }\end{array}$ & $\begin{array}{l}\text { The bag should be arranged so as to } \\
\text { prevent bridging in concave regions, } \\
\text { wrinkling, or other conditions that } \\
\text { reduce compaction pressure }\end{array}$ \\
\hline $\begin{array}{l}\text { (7) Vacuum } \\
\text { Valve }\end{array}$ & $\begin{array}{l}\text { Form a tight, leak-free connection } \\
\text { between the vacuum bag and a } \\
\text { vacuum pump }\end{array}$ & $\begin{array}{l}\text { Multiple vacuum valves can be used to } \\
\text { improve vacuum distribution within } \\
\text { the bag or triangulate leaks }\end{array}$ \\
\hline
\end{tabular}

\subsection{Air Evacuation (Debulking)}

In the absence of autoclave pressure, the evacuation of entrapped air and other volatiles is critical to the fabrication of high quality parts. Air extraction is thus a required step during the manufacturing of OoA prepreg composites. Two types of air extraction are usually carried out during the layup and cure of a composite part.

- "Debulking" consists of drawing vacuum using a temporary vacuum setup. Debulk steps are usually short (5 - $20 \mathrm{~min}$ ) and imposed periodically, after a small number of plies (1-3) are laid down. Debulking enables air extraction through a minimal number of layers, and promotes the close geometrical conformation of newly-deposed plies to the laminate or underlying tool.

- "Vacuum holds" consist of drawing vacuum on the final bagged configuration of the part, at room temperature. Vacuum holds are designed to extract the maximal amount of air prior to heated curing. Their duration is therefore a function of part size and prepreg permeability, and can be significant (up to $16 \mathrm{~h}$ or more, for large parts).

OoA prepreg plies are porous, containing continuous air paths (see section 2.2). These paths enable air extraction during debulking and/or a room-temperature vacuum hold. The extent of air extraction is primarily governed by the time spent under vacuum, the permeability of the prepreg 
stack, and the design of the composite part (i.e. the flow length scale required for extraction). Modeling air flow in porous prepreg, and predicting residual pressure as a function of material, part, and process factors, can therefore help in estimating appropriate debulk and vacuum hold times needed to extract entrapped volatiles. Any entrapped gasses will evolve during heating, some near the edge breathing may be evacuated, but those entrapped will pressurise according to the moisture equilibrium within the resin. No allowables for entrapped air are currently prescribed for OOA prepregs, however a cured void content below $2 \%$ is expected for aerospace grade composite materials.

\section{Modelling air extraction}

A classical model for air evacuation is subject to the following assumptions:

1. The air flow in the porous medium follows Darcy's Law for flow in porous media. The air velocity is therefore related to the prepreg permeability (described in section 2.3),

2. The air behaves as an ideal gas, and

3. Air mass conservation is ensured at each location in the prepreg.

Under these three assumptions, the constitutive equation obtained for the pressure field $\mathrm{P}$ is described by Cender, Simacek, Advani (2012), and Tavares, Michaud, Manson (2009):

$\frac{\partial \mathrm{P}}{\partial t}=\nabla \cdot\left(\frac{\boldsymbol{K}}{\mu\left(1-v_{f}\right)} \nabla P\right)$

where $\boldsymbol{K}$ is the permeability tensor, $\mu$ is the air viscosity, and $v_{f}$ is the fibre volume fraction (and thus $\left(1-v_{f}\right)$ is the porosity). Specific part and process situations will determine the geometry over which this constitutive equation has to be solved, along with the initial and boundary conditions.

\section{In-plane versus through-thickness extraction strategies}

Equation (5) can be solved for specific 3D geometries and boundary conditions, using numerical methods (e.g. finite element method). Nonetheless, to provide broad insights into air evacuation trends, two extremely simplified situations can be considered: the in-plane and through-thickness cases, summarized in Table 10. Each case is representative of an air extraction setup strategy. They both reduce to a one-dimensional problem.

Using a dimensionless analysis a master curve of pressure versus time can be obtained, as shown in Figure 14 (see Levy, Kratz, Hubert (2015)). The residual maximum pressure in the part follows an exponential decay according to the dimensionless time

$\tau=\frac{t \times K}{d^{2} \mu\left(1-v_{f}\right)}$

where $K$ is the permeability and $d$ the 1D domain length. Clearly, the pressure decay is fastest in the early portion of the vacuum hold, but requires an extensive time for complete evacuation. Using this solution for both in-plane and through thickness strategies, with the appropriate dimensionless times given in Table 10, the residual pressure in the part versus time can be calculated. This 
solution, and specific numeric values for material properties and part geometry, can then be used to determine the actual time required to reach a given pressure level.

Table 10 Simplified 1D air extraction strategies for OOA prepregs.

\begin{tabular}{|c|c|c|}
\hline & In plane & Through thickness \\
\hline Setup & n media (edge breather) & distribution media (with perforated release fim) \\
\hline Modelling & $\rightleftarrows \mathrm{L} / 2 \longrightarrow$ & $P=0$ \\
\hline & $k_{x x} \quad \mathrm{P}=0$ & $K_{z z}$ \\
\hline $\begin{array}{l}\text { Dimensionless } \\
\text { time }\end{array}$ & $\tau=\frac{t \times K_{x x}}{\frac{L^{2}}{4} \mu\left(1-v_{f}\right)}$ & $\tau=\frac{t \times K_{z z}}{h^{2} \mu\left(1-v_{f}\right)}$ \\
\hline
\end{tabular}

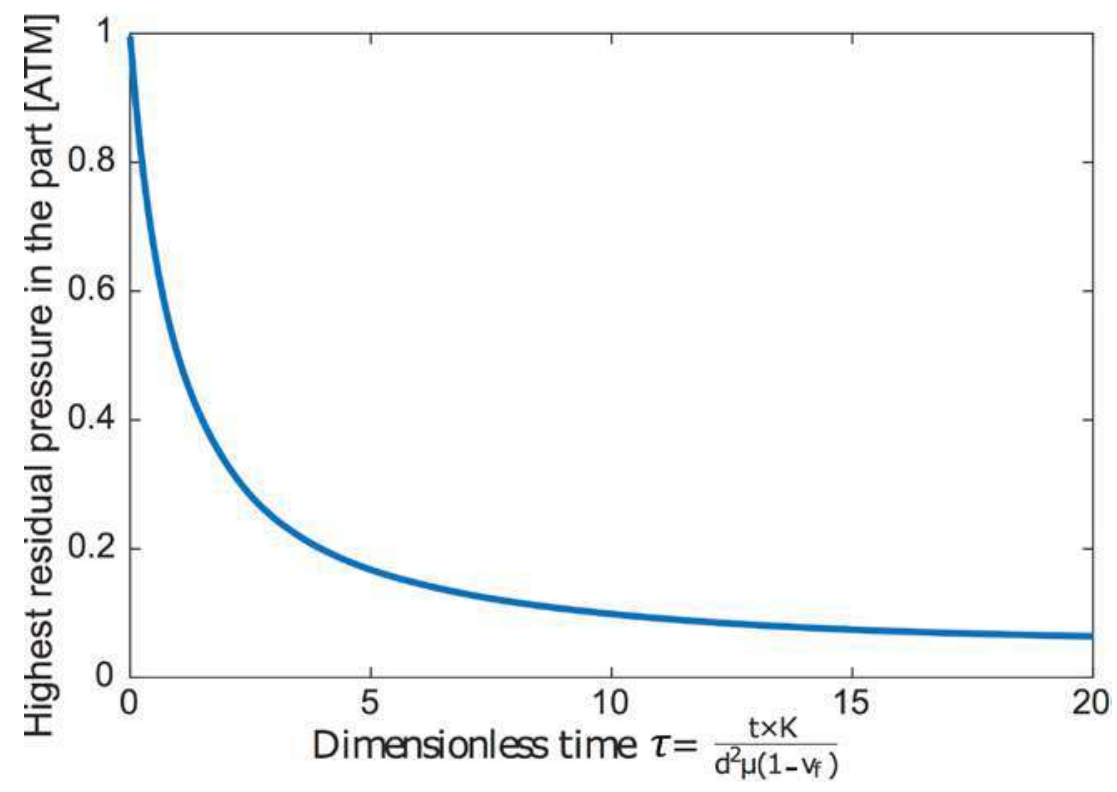

Figure 14 Master curve for the one-dimensional air extraction problem. For a given time $t$, permeability $K$, air viscosity $\mu$, dimension $d$ and fiber volume content $v_{f}$ the dimensionless time $\tau$ can be computed. Then, the residual maximum pressure in the part can be obtained (adapted from Levy, Kratz, Hubert (2015)).

\section{Critical length}

The typical impregnation format of OOA prepregs results in a highly anisotropic permeability tensor, with a relatively high capacity for in-plane air flow and low (or negligible) capacity for 
through-thickness flow, as discussed in section 2.3.The relative capacity and importance of inplane and through-thickness gas flow can thus be estimated using the "permeability" aspect ratio (Simacek, Advani (2004), Levy, Kratz, Hubert (2015)):

$$
\left(\frac{h}{L_{c}}\right)^{2} \frac{K_{x x}}{K_{z z}}
$$

where $h$ is composite thickness, $L_{c}$ a characteristic length of the composite part, $K_{x x}$ the in-plane permeability, and $K_{z z}$ the through-thickness permeability. In practice, for a given part geometry, the typical part dimensions must be compared to the characteristic length:

$$
L_{c}=2 h \sqrt{\frac{K_{x x}}{K_{z z}}}
$$

- For parts with in-plane dimensions larger than $L_{c}$, through-thickness air extraction, using perforated release film, will be faster.

- Conversely, for parts smaller than $L_{c}$, extracting air using in-plane strategies with edge breathing will be faster.

In practice, air evacuation is likely to occur in both in-plane and transverse directions. However, the extreme cases of purely in-plane and through-thickness gas flow clarify the physics of the air evacuation, and provide insights into which strategy is most likely (or preferred) for a given set of material and part characteristics.

\section{Application - design chart}

Figure 15 shows an illustration of the presented methodology adapted from Levy, Kratz, Hubert (2015). A flat part (4 mm thick) is considered. The in-plane and through-thickness permeabilities are $K_{\mathrm{xx}}=12 \times 10^{-14} \mathrm{~m}^{2}$ and $K_{\mathrm{zz}}=5 \times 10^{-17} \mathrm{~m}^{2}$, respectively. The fibre volume fraction is assumed to be 0.77 , The critical length is then $L_{\mathrm{c}}=0.39 \mathrm{~m}$. Figure 15 shows the maximum residual pressure in the part, versus time, for various in-plane dimensions. As discussed above, for a part larger than $L_{\mathrm{c}}=0.39 \mathrm{~m}$, through-thickness air extraction strategy is faster whereas for smaller in-plane dimensions, in-plane extraction is faster. This design chart shows, for instance, that for large parts, through-thickness air extraction will result is a residual pressure of $0.01 \mathrm{~atm}$ after $500 \mathrm{~s}$. 


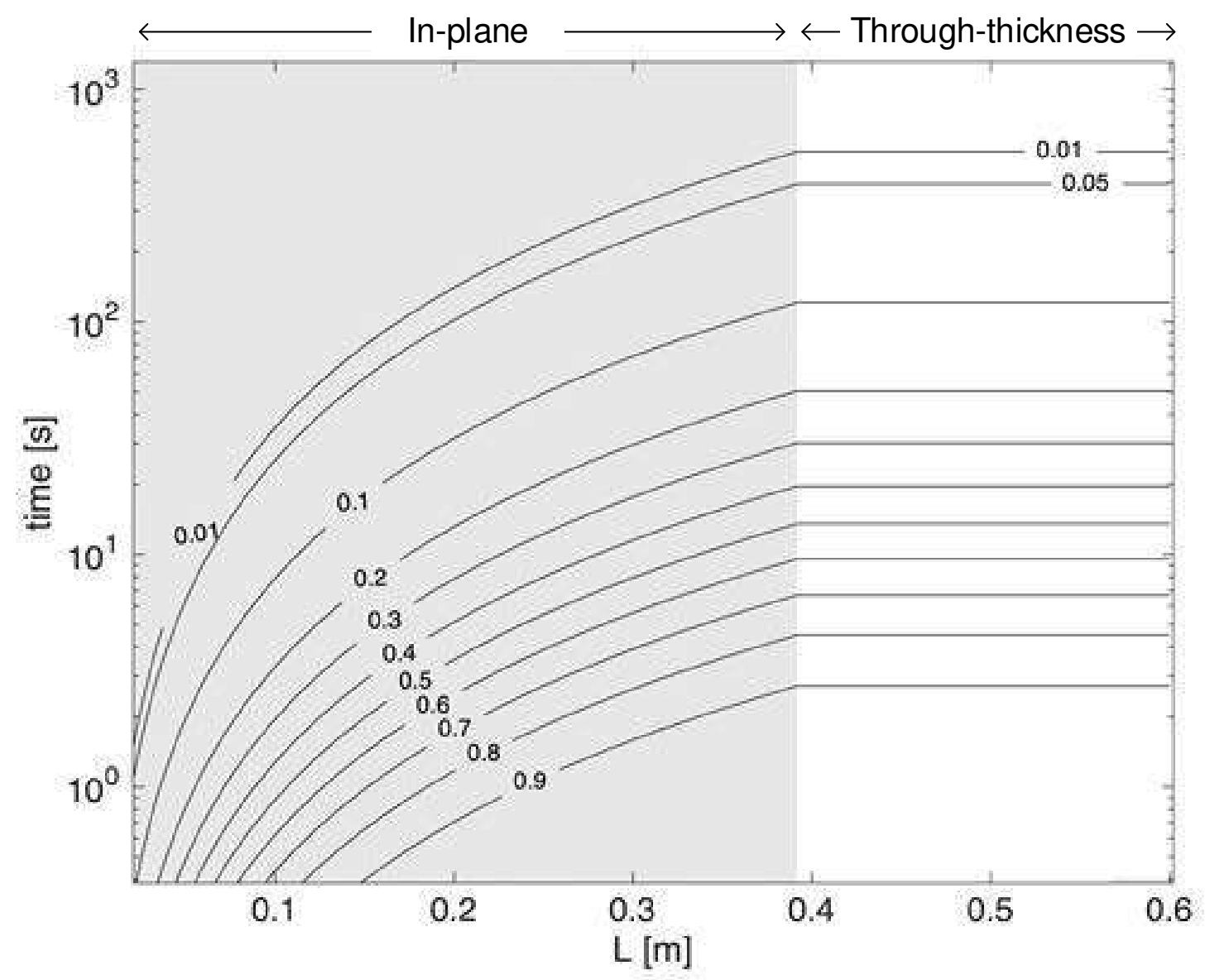

Figure 15 Application of air evacuation strategies for a $4 \mathrm{~mm}$ thick laminate. Iso-pressure in the part versus time and in-plane dimension. For a part with a critical in-plane dimension $L$ larger than $0.39 \mathrm{~m}$, through-thickness air extraction strategy is faster.

\subsection{Cure Cycle Selection}

The selection of an appropriate temperature cure cycle is one of the most important choices made during the development of an OOA prepreg manufacturing process. The cure cycle directly affects resin properties and, therefore, the consolidation phenomena that ultimately govern part quality. Furthermore, the cure cycle temperature and duration impact cycle time, production rate, equipment selection, and resource (energy) consumption.

The goal of cure cycle selection is to identify a time-temperature cycle that:

- Maximizes the thermal and mechanical properties of the matrix

- Limits flow-induced and gas-induced defects

- Minimizes curing time, energy consumption, and other resources

- Minimizes cost by allowing the use of simple, inexpensive infrastructure and tooling 
Furthermore, in the ideal case, the chosen cure cycle should be robust, or capable to accommodate reasonable expected temperature variations without the risk of significant quality degradation or other process failure.

Figure 16 shows a representative cure cycle for OOA prepreg processing, along with resin properties (degree of cure, viscosity, and glass transition temperature) for a typical OOA prepreg resin. The cure cycle consists of two distinct parts: the cure stage, and the post-cure stage. The room-temperature vacuum hold, discussed in the previous section, is omitted for clarity.

The cure stage comprises initial heat-up and one (or more) temperature dwells. The primary goal during cure is to enable full saturation of the fibre bed by resin during low-viscosity conditions (Figure 16, A), foster the removal of any air still entrapped in the part through bubble transport and/or shrinkage, gel the resin (Figure 16, B), and develop a sufficient amount of matrix strength, or "green" strength, to allow further processing. Therefore, cure is the critical period for microstructural quality.

Post-cure can be accomplished in vacuum-bagged conditions, immediately following cure (as in Figure 16), or can be free-standing, once sufficient green strength has been developed. On-tool post-cure is faster and simpler, and consists of a ramp and hold at the post-cure temperature. However, free-standing post-cure enables the use of cheaper, low-temperature cure tooling, and is theoretically amenable to batch processing. The primary goal of post-cure is to increase the glass transition temperature of the resin matrix (Figure 16, C) and maximize the resin degree of cure (Figure 16, D). Note that, in the case of free-standing post-cure, the resin should be vitrified prior to de-moulding, and the temperature during post-cure should never exceed the glass transition temperature in order to avoid devitrification and dimensional instability. 


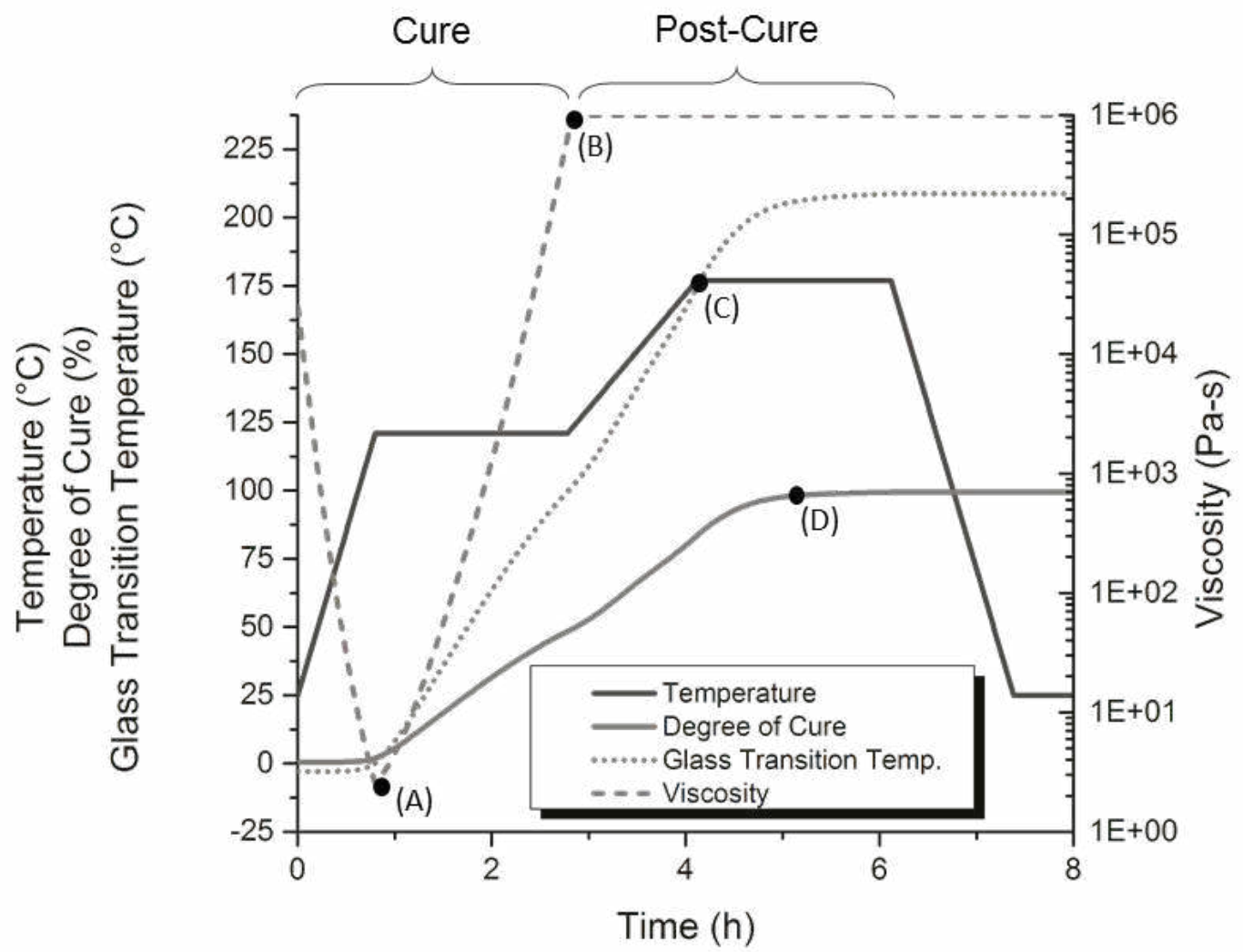

Figure 16 Representative cure cycle for OOA prepreg processing (post-cure on tool).

Cure cycle selection is complex and case-dependent, being constrained by material choices, equipment capabilities, and production requirements, and influenced by the need to minimize process-induced defects. The following discussion therefore highlights the major considerations involved in the cure cycle design process.

1. Material selection: The cure cycle must be compatible with the matrix resin. Typically, resin systems are supplied with one (or more) manufacturer-recommended cure cycles (MRCCs), which can be used in their original form or adapted to suit specific needs. In the latter case, any changes must allow sufficient time for resin flow, ensure that the resin gels and vitrifies, and never exceed the degradation temperature of the resin. Resin characterization tests and property models, such as described in Section 2, can help ensure these conditions are met.

2. Thermal lag: The heat-up rate of the oven is likely to exceed the heat-up rate of the part. This thermal lag is likely to be higher during OOA cure than autoclave cure, since oven heat transfer coefficients are lower than those encountered in autoclave due to the atmospheric pressure environment. The viscosity profile during cure (and, in particular, the minimum viscosity conditions shown in Figure 16, B) governs the rate of impregnation of the prepreg, and is critical to achieving full fibrebed saturation. Therefore, thermal lag should be monitored and mitigated, either by using embedded thermocouples for control or by appropriate compensation of the oven cycle. 
3. Exotherms: The lower cure temperature and slower cure kinetics of OOA prepreg resins (relative to autoclave systems) mitigate the risk of local exothermic heat-up, which can result in spatial differences in resin properties or, worse, matrix degradation. However, as with autoclave cure, the temperature in thick part sections should be analyzed using in-situ diagnostics and/or prior cure simulations to assess the risk of exotherms. Solutions to exotherms include lower-temperature cure and/or local heat transfer control (e.g. using a multi-zone heated tool).

4. Thermal gradients: Thermal lag, exotherms, part and tool design, and spatial variations in heat transfer conditions can lead to non-uniform temperatures within the curing part. A recent study has shown that, for OOA prepregs, thermal gradients can have a significant impact on part quality if resin infiltration occurs at the same time as air evacuation (Centea, Peters, Nutt (2015)). Thermal gradients affect the local rate of resin flow, leading to spatially non-uniform impregnation and in-plane permeability. Thermal gradients resulting in hotter-than-average interior regions of the part "drive" entrapped air towards the cooler edges, and lead to improved air evacuation and low void contents throughout the part, even with reduced vacuum quality (Figure 17, A). Conversely, hotter-than-average part edges effectively seal the laminate, preventing air removal and leading to significantly higher porosity in colder regions (Figure 17, B). Outside of porosity, thermal gradients may affect residual stress formation and lead to mechanical property variations before post-cure, though these effects are not unique to OOA cure. In general, if early air evacuation is successful, isothermal cure remains the simplest, most broadly acceptable curing strategy, and cure parameters should be chosen so as to ensure uniform thermal conditions. However, literature suggests that, in some cases, thermal gradients could be strategically implemented (using multi-zone heated tools, heating blankets, or tool design) to improve part quality.

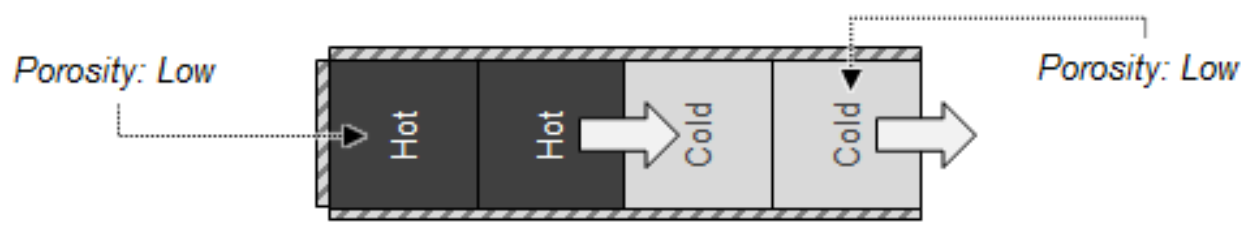

A) Cold-Side Breathing (Air Evacuation)

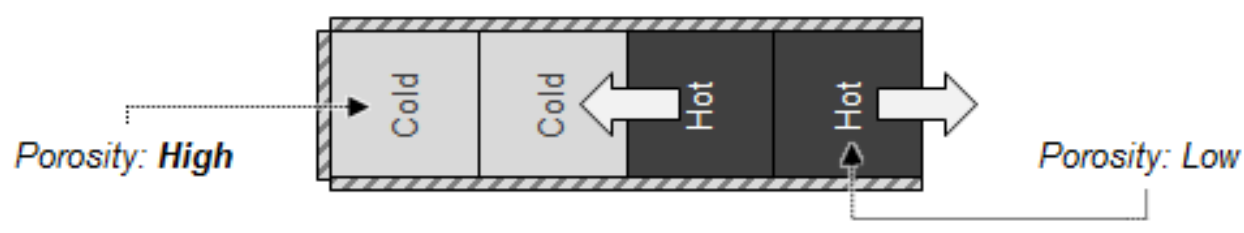

B) Hot-Side Breathing (Air Entrapment)

Figure 17 Thermal gradient effects on air evacuation and porosity, shown schematically for unidirectional cases of (A) cold-side breathing and (B) hot-side breathing.

5. Gas-induced porosity: Higher cure temperatures can raise the gas pressure within voids due to ideal gas behaviour, moisture vapourization, and other phenomena. For OOA cure, results derived from experiments and modelling have shown that typical cure temperatures can lead to void pressures that match or exceed the $0.1 \mathrm{MPa}$ available for vacuum bag-only 
consolidation, particularly if the resin has previously absorbed moisture (Grunenfelder, Nutt (2010)). Consequently, the benefits afforded by higher cure temperatures (e.g. faster cure) must be compared to the risk of elevated macro-porosity.

6. Flow-induced porosity: Higher cure temperatures can, however, lower the resin viscosity and enhance impregnation flow, reducing the likelihood of micro-porosity. The risk of incomplete fibre bed infiltration is typically low for commercially-available OOA prepregs, since resin rheology, fibre bed permeability, and manufacturer-recommended cure cycles are designed to ensure saturation. However, in cases of elevated out-time, literature has shown that faster heat-up rates and higher dwell temperatures can lower micro-porosity levels in cured parts, and effectively extend the out-life of OOA prepreg resin systems (Centea, Kratz, Hubert (2012)). This trend is exemplified in Figure 18, which shows model predictions for the final degree of impregnation achieved by two prepregs made up of the same resin system (Cytec Cycom 5320) but different fibre bed architectures (PW and 8HS), cured using heat-up ramps of $0.5-3^{\circ} \mathrm{C} / \mathrm{min}$ and dwells of $93^{\circ} \mathrm{C}$ or $121^{\circ} \mathrm{C}$, and exposed to out-time that led to initial resin degrees of cure of $a=0.01$ to $a=0.30$. These results show that, for both fibre beds, the higher ramp rates and hotter dwell temperatures increased the final level of prepreg saturation. The model development and material properties used for these predictions are described in Centea, Hubert (2012).

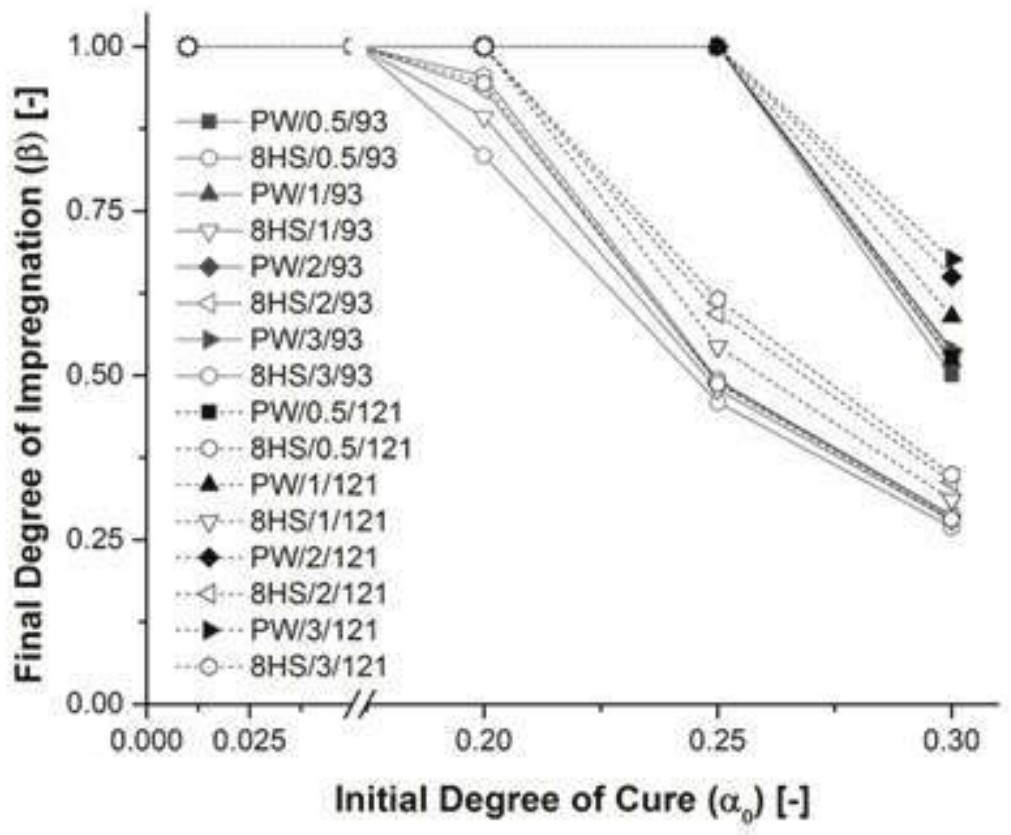

Figure 18 Model predictions for the effect of cure cycle, fibre bed architecture, and resin initial degree of cure on final degree of impregnation. The legend format is $[\mathrm{A} / \mathrm{B} / \mathrm{C}]$, where $\mathrm{A}$ is the fibre bed architecture, $\mathrm{B}$ is the ramp rate (in ${ }^{\circ} \mathrm{C} / \mathrm{min}$ ), and $\mathrm{C}$ is the dwell temperature (in ${ }^{\circ} \mathrm{C}$ ). The model development and material properties used for these predictions are described in Centea, Hubert (2012).

The selection of post-cure cycle parameters is comparatively straightforward, since the part microstructure is largely fixed after gelation (and, potentially, vitrification). The post-cure heat-up 
rate must be relatively low to avoid devitrification, particularly if the part is free-standing. Meanwhile, the post-cure temperature should ideally be as low as possible (or as close as possible to the expected service temperature), to limit the formation of residual stresses and processinduced deformations during cooling, enable the use of lower-temperature tooling, and reduce energy consumption.

Fortunately, despite this complexity, OOA prepregs can be cured using a wide range of cure cycles. The major cure cycle parameters, their effects, and typical values are summarized in Table 11.

Table 11 Major cure cycle parameters for OOA prepreg cure, their effects on part quality, and typical values for commercial materials.

\begin{tabular}{|c|c|c|}
\hline Parameter & Effects & Typical Value \\
\hline $\begin{array}{l}\text { Heat-up ramp } \\
\text { (cure) }\end{array}$ & $\begin{array}{l}\text { Faster heat-up ramps lead to: } \\
\Downarrow \text { Lower cycle times } \\
\Downarrow \text { Lower viscosity } \\
\Downarrow \text { Lower porosity (caused by out-time) }\end{array}$ & $0.5-3^{\circ} \mathrm{C} / \mathrm{min}$ \\
\hline $\begin{array}{l}\text { Dwell } \\
\text { (cure) }\end{array}$ & $\begin{array}{l}\text { Higher dwell temperatures lead to: } \\
\Downarrow \text { Lower cycle times } \\
\Downarrow \text { Lower viscosity } \\
\Downarrow \text { Lower porosity (caused by out-time) } \\
\Uparrow \text { Higher porosity (caused by moisture, air) }\end{array}$ & $80-130^{\circ} \mathrm{C}$ for $1-12 \mathrm{~h}$ \\
\hline $\begin{array}{l}\text { Heat-up ramp } \\
\text { (post-cure) }\end{array}$ & $\begin{array}{l}\text { Faster heat-up ramps (post-cure) lead to: } \\
\Downarrow \text { Lower cycle times } \\
\Uparrow \text { Higher risk of devitrification }\end{array}$ & $0.5^{\circ} \mathrm{C} / \mathrm{min}$ \\
\hline $\begin{array}{l}\text { Dwell (post- } \\
\text { cure) }\end{array}$ & $\begin{array}{l}\text { Higher dwell temperatures (post-cure) lead to: } \\
\Downarrow \text { Lower cycle times } \\
\Uparrow \text { Higher risk of residual stresses }\end{array}$ & $180^{\circ} \mathrm{C}$ for $1-2 \mathrm{~h}$ \\
\hline
\end{tabular}

\section{Sandwich panels}

Sandwich panels enable designers to create very efficient structures capable of resisting deformation to high bending and torsional loads. The core material resists the shear loads of stiff composite facesheets spaced away from the neutral axis, increasing the second moment of area of the structure. The most common core materials used for advanced composite sandwich panel construction include polymer foams, such as Polyvinyl chloride (PVC), polymethacrylimide (PMI), and honeycomb cores made from either aramid paper or aluminium foil. Closed-cell polymer foam cores offer many appealing characteristics for OOA processing as summarized in Table 12. As a result, foam core sandwich panels can be treated very similarly to laminates, with special attention paid to complex shapes. Honeycomb cores typically have higher mechanical properties and operational temperatures than foam cores, however they do have some serious processing drawbacks. Honeycomb cores entrap a large volume of volatiles (air at humidity level 
of lay-up room), and aramid paper honeycomb cores release absorbed moisture by diffusion when heated. High gas pressures within the individual cells increases the likelihood for gas-induced porosity in the composite facesheet, as discussed in section 4.3.

Table 12. Sandwich core properties relevant for out-of-autoclave processing.

\begin{tabular}{|l|l|l|l|l|}
\hline $\begin{array}{l}\text { Core } \\
\text { material }\end{array}$ & $\begin{array}{l}\text { Processing } \\
\text { temperature } \\
\left({ }^{\circ} \mathbf{C}\right)\end{array}$ & $\begin{array}{l}\text { Processing } \\
\text { pressure (kPa) }\end{array}$ & $\begin{array}{l}\text { Volatiles } \\
\text { entrapped during } \\
\text { lay-up }\end{array}$ & $\begin{array}{l}\text { Volatile release } \\
\text { during } \\
\text { processing }\end{array}$ \\
\hline PVC & $<120$ & 100 & No & No \\
\hline PMI & $<130$ & 300 & No & No \\
\hline Aramid & 180 & 500 & Yes & Yes \\
\hline Aluminium & 180 & 500 & Yes & No \\
\hline
\end{tabular}

Honeycomb sandwich panels can be manufactured if the gas pressure within the core is correctly managed throughout the manufacturing process. Some pressure within the core may aid skin consolidation and minimize adhesive foaming, however, if the core pressure is too high, voids will form in the facesheet or create disbonds. The optimal honeycomb core pressure range will be specific to the sandwich construction to be manufactured (Grove, Popham, Miles (2006), Rion, Stutz, Leterrier, Manson (2009), Tavares, Caillet-Bois, Michaud, Manson (2010)). For example, cores with larger cell diameters may require thicker skins, lower vacuum levels in the bag, or higher internal core pressures to stabilize the core and reduce skin voidage. Arriving at the optimal core pressure is governed by the pressure sinks and sources in the manufacturing process. The honeycomb core pressure will decrease given the air permeability of the skin and the bag vacuum level, and increase due to gas expansion arising from increasing temperature and the presence of moisture or other volatiles.

If we consider a repeating unit cell of a honeycomb sandwich panel, comprised of six paper cell walls (with four shared between cells and two full walls in each cell) bounded by two composite facesheets, the total pressure in the honeycomb cells, $P_{\text {Cell }}$, can be calculated at time step, $\Delta t$, using the ideal gas law equation of state and by assuming that neither air or water molecules are biased during outflow:

$P_{\text {Cell }}=\frac{R_{u} T}{V_{\text {Cell }}}\left[\frac{m_{\text {Air }, i}}{\omega_{\text {Air }}}+\frac{\left(M_{\text {Vapor }}+\dot{m}_{\text {Honeycomb }} \Delta t\right)}{\omega_{\text {Vapor }}}-\dot{m}_{\text {Bag Skin }} \Delta t\left(\frac{\gamma_{\text {Air }}}{\omega_{\text {Air }}}+\frac{\gamma_{\text {Vapor }}}{\omega_{\text {Vapor }}}\right)\right]$

where $R_{u}$ is the universal gas constant, $T$ is the temperature, $V_{\text {Cell }}$ is the empty volume of the honeycomb core, $\gamma$ is the mass fraction of air and water vapour in the cell, and $\omega$ is the molar mass of air and water vapour (Kratz, Hubert (2015)). The model predicts pressure based on the current mass of air and water vapour in the honeycomb cell, which is comprised of the moisture influx from the cell walls, $\dot{m}_{\text {Honeycomb }}$, and the outflow of moist air through the permeable bag-side skin,

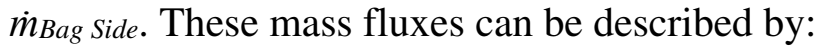


$\dot{m}_{\text {Honeycomb }}=-D \rho A_{S}\left(\frac{M_{\text {Paper }}}{M_{U, \text { Paper }}}-\frac{M_{\text {Cell }}}{M_{U, \text { Cell }}}\right)$

where $D$ is the diffusion coefficient, $A s$ is the surface area of the honeycomb cells, $M$ is the percent moisture content, $M_{U}$ is the percent moisture by mass at $100 \%$ relative humidity, and

$\dot{m}_{\text {Bag Skin }}=-\frac{\rho K A}{2 \mu h}\left(\frac{P_{B a g^{2}-P_{C e l l}}{ }^{2}}{P_{B a g}}\right)$

where $K$ is the permeability coefficient, $A$ is the cross-sectional area normal to flow, $\mu$ is the fluid viscosity, $P_{B a g}$ is the vacuum bag pressure, $h$ is skin thickness. $\rho$ is the density of the gas. The effect of the parameters that influence the honeycomb core pressure are summarized in Table 13.

Table 13 Material and process parameters influencing honeycomb core pressure.

\begin{tabular}{|l|l|l|}
\hline Parameter & Type & Significance \\
\hline$K$ & Material property & $\begin{array}{l}\text { Reduces } P_{\text {Cell }} \text { by allowing gas flow through the bag- } \\
\text { side skin }\end{array}$ \\
\hline$D$ & Material property & $\begin{array}{l}\text { Increases } P_{\text {Cell }} \text { by introducing moisture into the cell } \\
\text { void space }\end{array}$ \\
\hline$P_{\text {Bag }}$ & Process condition & $\begin{array}{l}\text { Determines } P_{\text {Cell }} \text { at the start of elevated temperature } \\
\text { processing based on } K \text { and time. }\end{array}$ \\
\hline$M_{\text {Paper }}$ & Process condition & $\begin{array}{l}\text { Influences the mass of water vapour introduced into } \\
\text { the cell void space }\end{array}$ \\
\hline$P_{\text {Consolidation }}$ & Process condition & $\begin{array}{l}\text { Applies external consolidation pressure to the } \\
\text { honeycomb skins }\end{array}$ \\
\hline
\end{tabular}

The honeycomb core pressure is evidently a key processing parameter that influences consistent, predictable part quality for OOA honeycomb panels. Major defects have been observed in cured parts when the honeycomb core pressure equals or exceeds the consolidation pressure at during elevated temperature processing (Kratz, Hubert (2011)). If this occurs near gelation, the panel will likely be scrapped, however, consistent part quality is more likely if the honeycomb core pressure remains below the applied consolidation pressure throughout processing.

The parameters likely to change in a manufacturing environment include the influence of air permeability of different prepreg formats (see Table 4), percent moisture absorption in the honeycomb core, and the initial honeycomb core pressure at the start of curing. These parameters can be varied independently using the model presented in Eq. (8). The simulations result in a 3dimensional surface plot of pressure as a function of skin air permeability and core moisture content. An example where the initial core pressure was 50 mbar is shown in Figure 19. If the combination of moisture and skin permeability creates a condition where the maximum core pressure during elevated temperature processing exceeds $1000 \mathrm{mbar}$, the honeycomb core pressure moves from the light (below atmospheric pressure) region into the dark (above atmospheric pressure) region of the graph. 


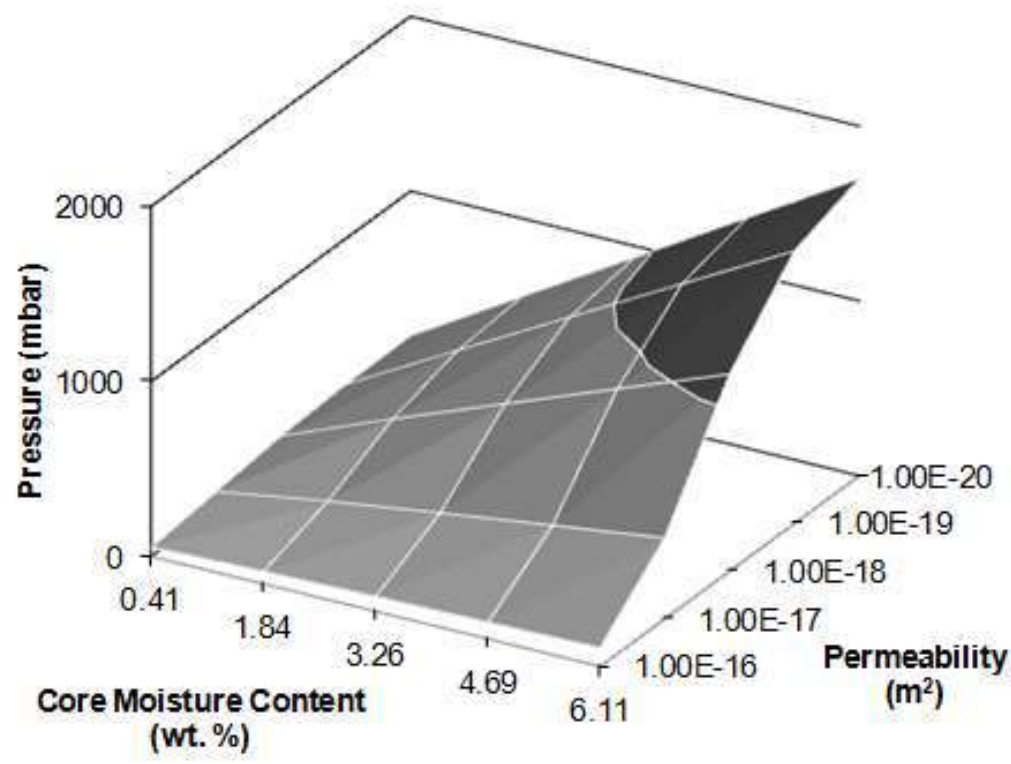

Figure 19 Surface plot showing the maximum honeycomb core pressure observed during cure with increasing core moisture and decreasing skin permeability. The initial core pressure in this plot was 50 mbar.

Multiple surfaces can be created with increasing initial honeycomb core pressures. Overlaying these plots onto a 2-dimensional contour can provide a process map to identify what combination of initial core pressure, material air permeability during processing, and core moisture content is needed to prevent the honeycomb core pressure from exceeding the process consolidation pressure. This was done for two consolidation pressures in Figure 19. A 1000 mbar of consolidation pressure, would be achieved by a high vacuum level (20-30 mbar) at sea level, and is presented alongside a scenario where a reduced consolidation pressure of $800 \mathrm{mbar}$ was encountered during processing. The reduced consolidation pressure could be caused by tooling leaks, poor bagging, insufficient vacuum pump capacity, moisture off-gassing of the consumable materials, or manufacturing at altitudes higher than sea level. As a consequence, process robustness suffers with reduced consolidation pressure. 

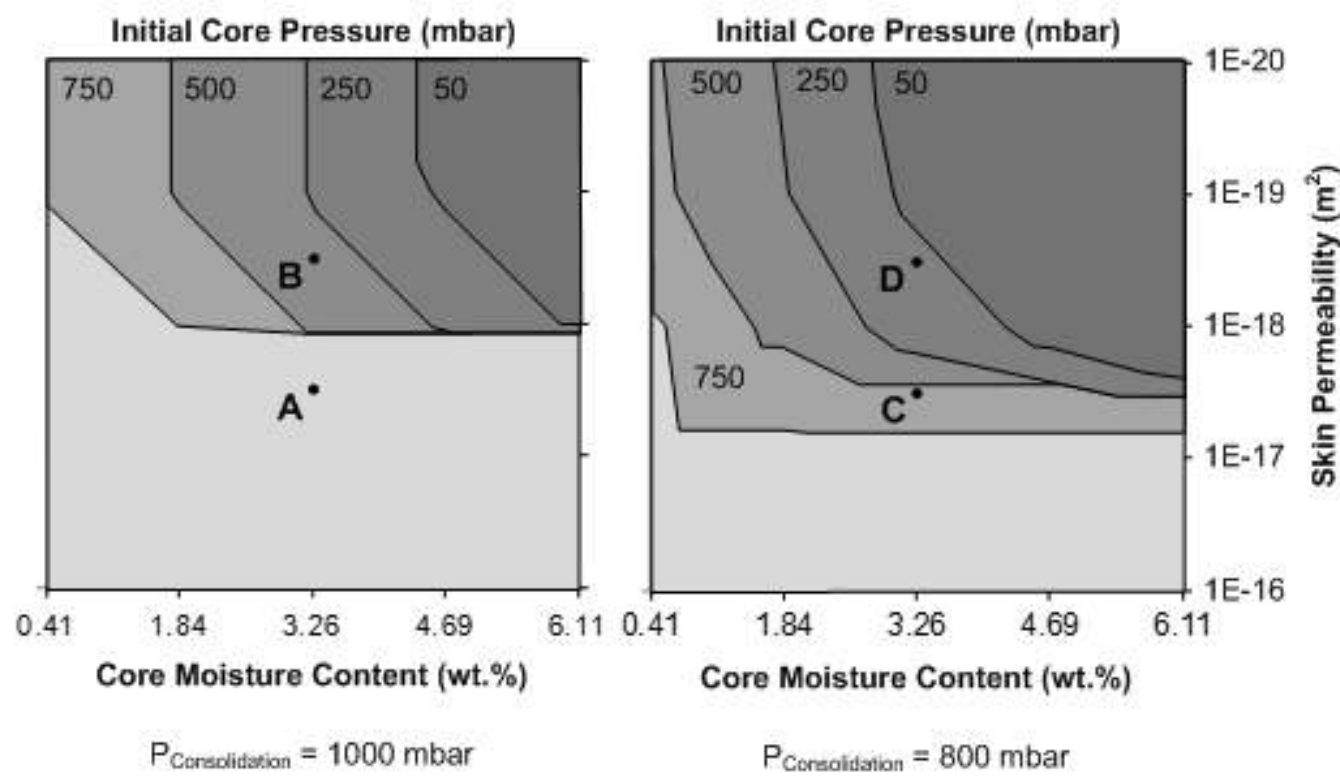

Figure 20. Process maps for honeycomb core pressure during $121^{\circ} \mathrm{C}$ processing cycle with 1000 mbar (left) and 800 mbar (right) of consolidation pressure. The honeycomb core pressure remains below the consolidation pressure in the light area and exceeds the consolidation pressure in the dark area.

These process maps can be used to identify if core pressure could exceed the consolidation pressure during processing. For example, cores that have reached a moisture equilibrium at $50 \% \mathrm{RH}$, no $\mathrm{P}_{\text {Cell, }}$ at point $\mathrm{A}$ will cause the core pressure to equal the consolidation pressure during processing. If skin air permeability was reduced, as in point $\mathrm{B}, \mathrm{P}_{\text {Cell, } \mathrm{i}}<250 \mathrm{mbar}$ is required for the core pressure to remain below the consolidation pressure throughout processing. For the same prepreg and core moisture content, at point $\mathrm{C}, \mathrm{P}_{\text {Cell, i }}<500 \mathrm{mbar}$ and at point $\mathrm{D}, \mathrm{P}_{\text {Cell,i }}<50 \mathrm{mbar}$ for the honeycomb core pressure to remain below the reduced consolidation pressure.

In practice, these process maps could be used to select materials or solve processing issues for aramid paper honeycomb sandwich panels. If poor quality parts are being fabricated, five options can be considered to move the peak (predicted) honeycomb core pressure from the dark (above atmospheric pressure) to the light (below atmospheric pressure) regions of the process map:

1. Process modifications: The consolidation pressure can be increased by improving the vacuum level achieved under the vacuum bag. This could be achieved by fixing tooling leaks, improving vacuum pump capacity and/or achievable vacuum level.

2. Tighter process controls: The layup room humidity set-points can be lowered or creative solutions may be needed to dry the honeycomb core, and then prevent or slow moisture adsorption during the lay-up process.

3. Improving the skin air permeability: The pre-processing air permeability of the honeycomb skin can be characterized as outlined in Section 2.3, and the duration of the pre-processing vacuum hold can be increased based on the predictions (Table 10) to lower the initial honeycomb core pressure. If the permeability results in a time-consuming vacuum hold that limits production, perforating the skins can reduce the pre-processing vacuum hold 
period (Tavares, Caillet-Bois, Michaud, Manson (2010)), or selecting a combination of skin materials (prepreg and adhesive films) with higher air permeabilities can be considered.

4. Processing cycle: Modifying the temperature profile could improve panel quality but change cured resin physical properties. Increasing the time spent at maximum air permeability (by introducing a devolatilization dwell), or lowering the cure temperature could be considered to reduce the honeycomb core pressure observed during cure.

5. Selecting a different honeycomb core: Korex ${ }^{\circledR}$ or Kevlar $^{\circledR}$ based honeycomb cores may be more suitable than Nome ${ }^{\circledR}$ for OOA manufacturing because they absorb less moisture. As a result the honeycomb core pressures observed during processing would be reduced. However, these alternative cores are more expensive.

The ultimate requirement for sandwich structures is that the bond between the composite facesheet and core is stronger than the tensile strength of the core. This can be assessed by a flatwise tensile strength test according to ASTM C297. If core failure is observed, as shown in Figure 21, the bondline quality is sufficient to avoid in-service adhesive failure. Adhesive strength is expected to deteriorate at elevated temperatures and in the presence of moisture, therefore testing would need to be performed at the extreme environmental conditions encountered in service to ensure reliable performance.

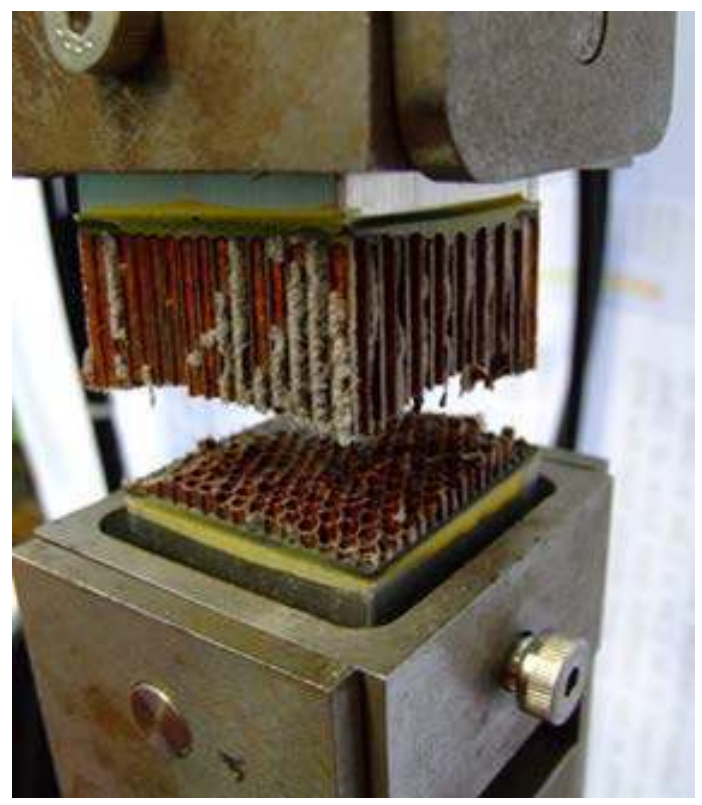

Figure 21. Flatwise tensile test of a honeycomb sandwich construction showing $100 \%$ core failure.

\section{Complex shape parts}

Manufacturing complex shape laminates will often lead to defects, especially when parts include intricate features. The typical defects include corner thickness deviation, porosity and fibre wrinkling. Studying the L-shape laminate, or corner geometry, gives a first insight on the defects that may appear in any industrial complex geometry. In the case of most OOA semi-prepreg composite, the high bulk factor will result in large corner thickness deviation from the nominal 
thickness obtained on flat plates. In corner regions, because of the curvature, the material will undergo a different compaction compared to flat areas:

- Interply friction might constrain the layers from conforming to the mould, thus preventing an adequate compaction in the corner.

- Reaction stress is different in the corner and in the flat regions. This leads to a different compaction pressure and a different final thickness in the corner.

Figure 22 illustrates a typical corner laminate configuration before and after cure. The female or male tool radius, $R_{m}$, and the flange length, $L_{m}$, defines the geometry of the corner. The laminate final thickness in the flange area, $t_{f}$, corresponds to the cured ply thickness of the prepreg system used and $t_{f}^{c}$ is the final corner thickness. The corner thickness deviation is defined as $\Delta t_{c}=\frac{t_{f}^{c}-t_{f}}{t_{f}}$

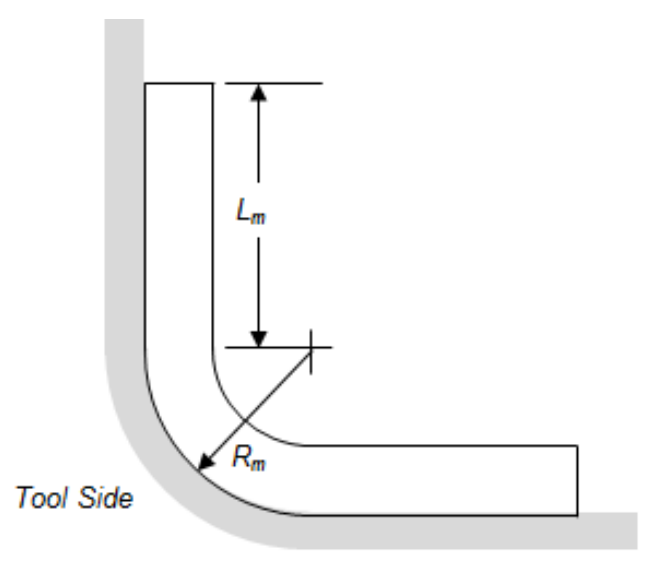

A) Female tool - initial

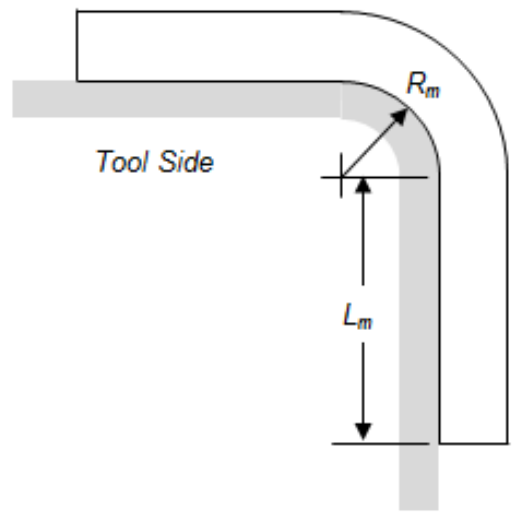

C) Male tool - initial

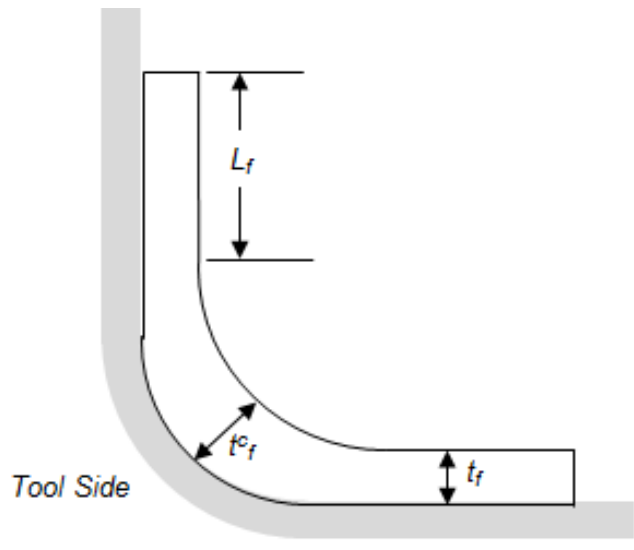

B) Female tool - final

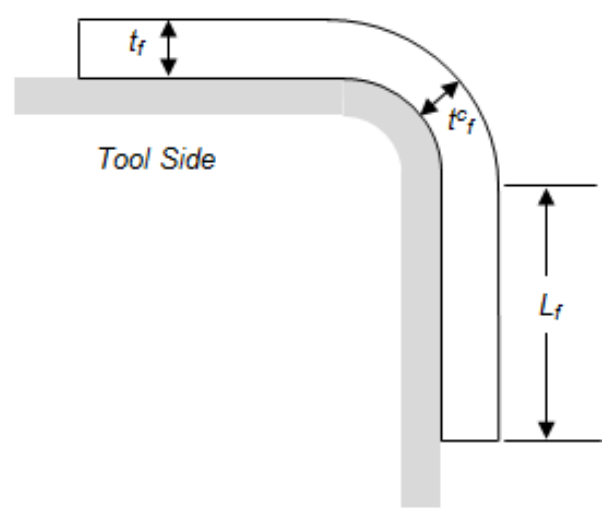

D) Male tool - final

Figure 22 Corner laminate geometrical definition, $R_{m}=$ tool radius, $L_{m}=$ flange length, $t_{f}=$ final flange thickness, $t_{f}^{c}=$ final corner thickness, A) Female tool initial, B) Female tool final, C) Male tool initial, D) Male tool final. 


\subsection{Semi-empirical model for corner thickness deviation}

Experimental studies of the corner thickness deviation show a significant variability in corner thickness change depending on tooling, material, laminate and processing conditions (Brillant, Hubert, (2010)). Nevertheless, a general model was proposed to provide a first approximation of the corner deviation (Levy, Stadlin, Hubert, (2014)).

First, the conformation number $\Lambda_{\mathrm{N}}$ is defined as

$\Lambda_{N}=\frac{R_{m}}{\mu L_{m}}$

where $\mu$ is the interply coulomb friction coefficient, $R_{m}$ the tool radius, and $L_{m}$ the flange length. The dimensionless conformation number is an indicator of whether the compaction is friction or pressure dominated. If $\Lambda_{N}<1$, the interply friction limit is not reached in the flange, and the outermost ply will not conform to the corner. This is a friction dominated compaction. If $\Lambda_{N}>1$, the friction limit is reached, and the first ply can slip, thus contacting the second ply. The compaction is now pressure dominated.

The two extreme case of friction dominated, $\Delta t_{c}{ }^{F}$ and pressure dominated $\Delta t_{c}{ }^{P}$ corner thickness deviation can be expressed as a function of the laminate and tooling parameters and the prepreg bulk factor, $\beta$ (Table 14).

Table 14 Equations for the corner thickness deviation computation.

\begin{tabular}{|l|c|c|}
\hline & $\begin{array}{c}\text { Friction dominated } \\
\Delta t_{c}^{F}\end{array}$ & $\begin{array}{c}\text { Pressure dominated } \\
\Delta t_{c}^{P}\end{array}$ \\
\hline Female tool & $(1-a)(\sqrt{2}-1)$ & $(\beta-1) \frac{t_{f}}{R_{m}}$ \\
& where $a=\frac{2-\frac{\pi}{2} \beta}{2-\frac{\pi}{2}}$ & \\
\hline Male tool & $\sqrt{2}(a-1)-1$ & $-(\beta-1) \frac{t_{f}}{R_{m}}$ \\
& where $a=\frac{\beta\left(\frac{\pi}{2}-4\right)}{\frac{\pi}{2}-2}$ & \\
\hline
\end{tabular}

An empirical rule of mixture is proposed for the relative corner thickness deviation:

$\Delta t_{c}=\frac{t_{f}^{c}-t_{f}}{t_{f}}=g\left(\Lambda_{N}\right) \times \Delta t_{c}^{P}+\left(1-g\left(\Lambda_{N}\right)\right) \times \Delta t_{c}^{F}$

where $g\left(\Lambda_{N}\right)$ is a step function of the conformation number $\Lambda_{N}$. 
The step function $g\left(\Lambda_{N}\right)$ depends on material variability, layup operations and other factors. The transition between the two regimes is not sharp and $g\left(\Lambda_{N}\right)$ is likely to be smoother than the ideal step function. It should nonetheless ensure that $g\left(\Lambda_{N}\right) \rightarrow 0$ when $\Lambda_{N} \rightarrow 0$ and $g\left(\Lambda_{N}\right) \rightarrow 1$ when $\Lambda_{N} \rightarrow+\infty$. An empirical fitting is suggested using the classical smoothed step function:

$g\left(\Lambda_{N}\right)=\frac{1}{2}+\frac{1}{2} \tanh \left(\frac{\Lambda_{N}-a}{b}\right)$

where $\mathrm{a}$ and $\mathrm{b}$ are determined experimentally. Table 15 shows typical values of $a$ and $b$ for different materials and tooling conditions.

Table 15 Parameters for the corner deviation model.

\begin{tabular}{|l|l|l|}
\hline & $\boldsymbol{a}$ & $\boldsymbol{b}$ \\
\hline Female tool & 0.50 & 1.00 \\
\hline Male tool & 0.50 & 0.60 \\
\hline
\end{tabular}

The following design charts have been generated and can serve as guidelines for the tooling design of corner laminates made of out-of-autoclave prepregs. For female mould (Figure 23) and for male mould (Figure 24). 


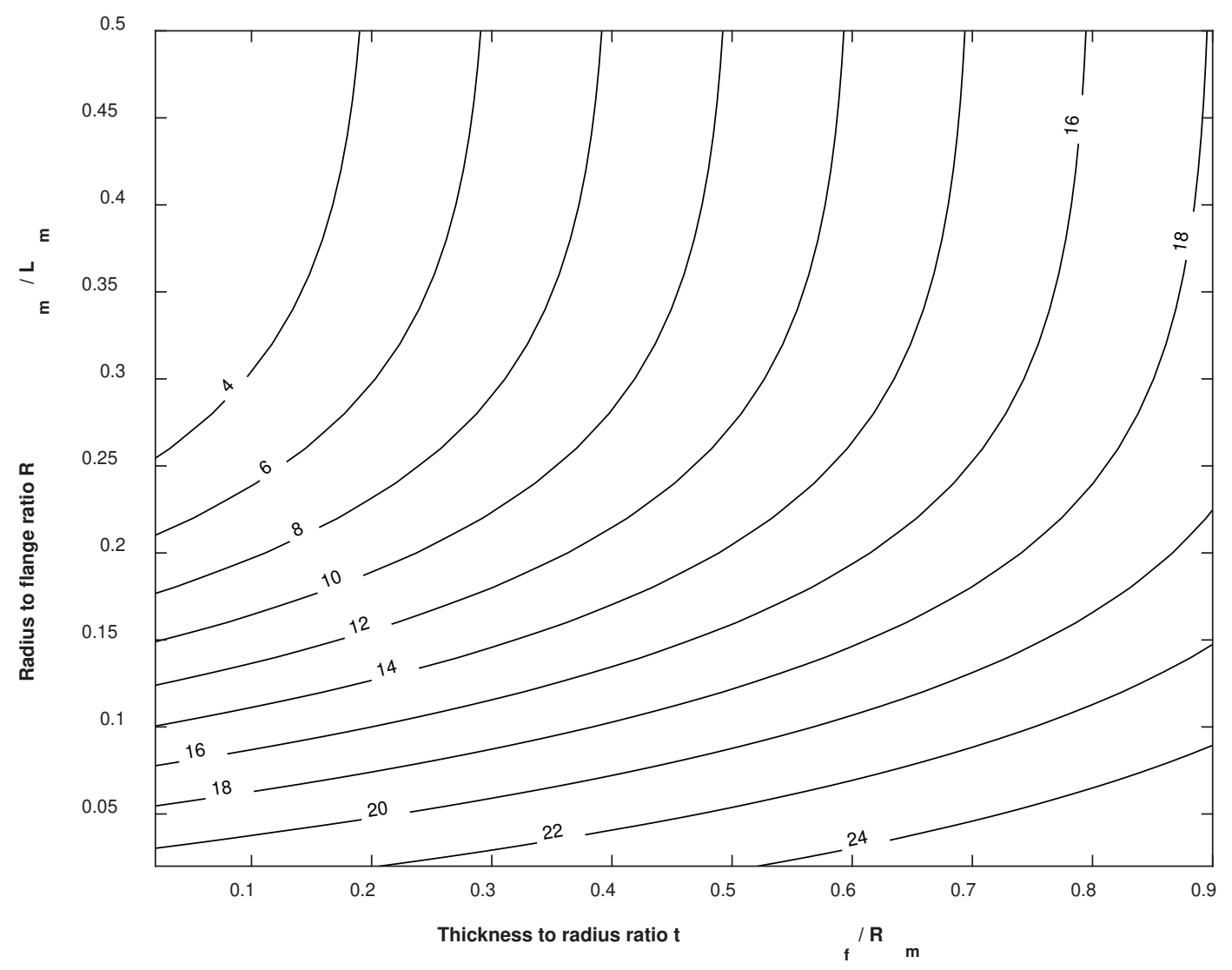

Figure 23 Corner thickness deviation (\%) for female tool (8HS prepreg). The thicker the laminate the higher the thickness deviation in the corner. This is because of the lower available compaction pressure. Also, the larger the flange, the higher the deviation, because plies cannot conform to the mould corner, due to interply friction. 


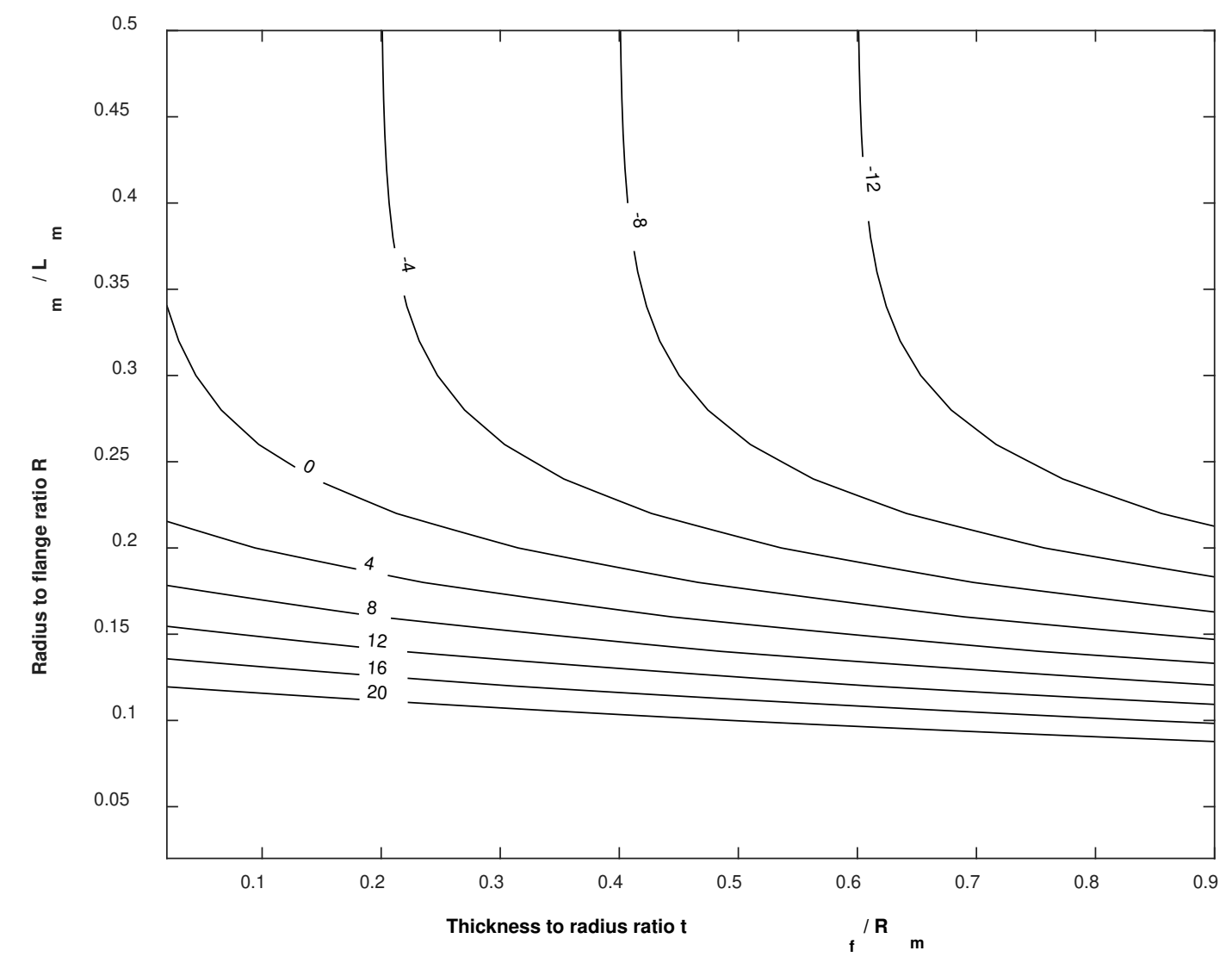

Figure 24 Corner thickness deviation (\%) for male tool (8HS prepreg).

\subsection{Additional effects}

Several manufacturing factors can influence the corner thickness deviation. A number of experimental studies compiled from various research papers were used to extract a corner deviation correction factor (Hughes, Hubert (2013), Krumenacker, Hubert (2015), Brillant, Hubert, (2010)). This factor can be used to estimate the effect of typical design changes that can be made to the processing of corner with OOA prepreg. Table 16 summarizes the values for the corner deviation factor for different manufacturing modifications.

Table 16 Corner deviation correction factor, $\Delta t_{c}=k \Delta t_{c}^{0}$.

\begin{tabular}{|l|l|}
\hline Case & $\boldsymbol{k}$ \\
\hline Pressure intensifier & 0.5 \\
\hline $50 \%$ Reduced, Restricted air evacuation & 1.5 \\
\hline Layup $<25 \%[0]$ & 0.7 \\
\hline Layup $>75 \%[0]$ & 1.4 \\
\hline
\end{tabular}




\begin{tabular}{|l|l|}
\hline Shape complexity (U shape) & 2.6 \\
\hline Tool angle $(90+\alpha)^{\circ}$ & $1-0.02 \alpha$ \\
\hline
\end{tabular}

$\Delta t_{c}^{0}$ is the corner deviation for a $90^{\circ}$ angle cross-ply laminate processed with nominal conditions (full vacuum, edge breathing). It can be estimated with eq.(12) or Figures 23 and 24.

\section{Cost analysis}

OOA prepreg processing can lower costs relative to autoclave cure by reducing capital and operating expenses associated with a pressurized vessel. Thus, OOA prepregs can alleviate two problematic scenarios for autoclave cure:

1) The low cost fabrication of small volumes of high quality parts, which has typically been impeded by the high fixed costs associated with autoclave vessels and autoclave-capable tooling.

2) The production of large integrated structures, for which sufficiently wide autoclaves are unavailable or prohibitively expensive.

The detailed cost structure (and savings) associated with OOA prepregs depends on part design, material selection, equipment choices, production line specifics, and protocols unique to each part, company, and industry. As a result, cost analysis is challenging. Nevertheless, models that estimate costs, even if simple, can provide insights into the relative performance of competing processes and identify technical goals that lead to cost reductions.

The cost structure of OOA prepreg processing was recently estimated by a few authors (Witik et al (2012), Tong (2012), Centea, Nutt (2016)) using technical cost modelling. Typically, processing steps were assumed to occur sequentially, and case studies focused on hand-laid, oven-cured smallor medium-size laminates using dedicated infrastructure. Results estimated that material costs contribute most strongly to total part costs, from $75 \%$ for small-sized parts to over $90 \%$ for larger parts. The remaining costs consist of labour and equipment, with labour higher for small parts due to overhead, and equipment costs higher for large parts due to higher capital expenditures, lower production rates, and higher depreciation per part. Material costs are largely driven by high prepreg (or carbon fibre) prices, with consumables contributing less than $10 \%$. The costs per part of equipment amortization (low-cost ovens and supporting infrastructure), maintenance, and energy were comparable. Human activity resulting in wages accounted for $15 \%$ (or less) of manufacturing time, while time-consuming steps were dominated by ply debulking, room-temperature vacuum holding, and cure. These results were derived from simple, generic case studies, and are unlikely to match a specific manufacturer's cost structure. However, they suggest the following means of cost reduction:

1. Reduce prepreg costs: The raw material cost of the prepreg was identified as the largest driver of specific total costs, and lower material consumption led to commensurate changes in part costs. Hence, the use of lower-cost prepreg and/or the net reduction of in-process material waste is the most direct method for decreasing manufacturing costs.

2. Larger part dimensions: Larger part dimensions were predicted to lower specific total costs despite an increase in infrastructure size due to amortization of fixed and labour costs over 
a higher amount of material. However, eventually, the increase in vacuum hold time associated with longer flow distances for air evacuations was estimated to increase cycle times, reduce production rates (assuming sequential manufacturing), raise equipment depreciation per part, and reverse this beneficial trend. Consequently, the development of materials and methods that allow rapid and/or size-independent air evacuation could decrease costs per part for large structures.

3. Rapid manufacturing: The effects of thermal cure cycle (heat-up rate, isothermal hold temperature), resin cure kinetics, and energy cost were predicted to have a lower impact on specific part costs than prepreg costs or amortization of capital costs. However, the ability to process OOA prepregs rapidly (through infrastructure that enables rapid heating and cooling, or through reformulated, fast-curing resins) can lead to higher production rates and reductions in energy consumption - and, in extremis, disrupt the traditional use of OOA prepregs by enabling applications in high-volume sectors.

\section{Future developments}

OOA manufacturing technology is continuously evolving as new material systems are designed and more applications are developed. A comprehensive review of the scientific work on the processing of OOA and on challenges such as scale-up and material variability was prepared by Centea et al. (Centea, Grunenfelder, Nutt (2016)). They identified a number of challenges that have to be addressed to improve OOA processing robustness and cost. Table 17 presents the OOA development roadmap showing state-of-the-art and future development needs.

Table 17 OOA development roadmap.

\begin{tabular}{|c|c|c|}
\hline & State if the art & Future development \\
\hline Materials & $\begin{array}{l}\text { - Optimized resin systems } \\
\text { - } \text { Fabrics and } \\
\text { unidirectional } \\
\text { - Different impregnation } \\
\text { strategies }\end{array}$ & $\begin{array}{l}\text { - Tailored impregnation for } \\
\text { application } \\
\text { - Online inspection } \\
\text { - Material systems for automation }\end{array}$ \\
\hline Tooling & $\begin{array}{l}\text { Wide range of tooling } \\
\text { material }\end{array}$ & $\begin{array}{l}\text { - Heated tooling } \\
\text { - } \quad \text { Cure monitoring integration } \\
\text { - } \text { Additive manufacturing for } \\
\text { tooling and inserts }\end{array}$ \\
\hline Layup & $\begin{array}{ll}\text { - } & \text { Edge breathing } \\
\text { - } & \text { Bagging methods to } \\
& \text { provide air evacuation } \\
\text { - } & \text { Heated debulk }\end{array}$ & $\begin{array}{l}\text { - Automation of fabric layup } \\
\text { - Reduction and recycling of scrap } \\
\text { prepreg }\end{array}$ \\
\hline Curing & $\begin{array}{l}\text { - Oven cure } \\
\text { - Limited use of heated } \\
\text { tooling }\end{array}$ & - Tailored heated tooling \\
\hline
\end{tabular}




\begin{tabular}{|c|c|c|}
\hline Design tool & $\begin{array}{c}\text { - Complete understanding } \\
\circ \quad \text { thermal } \\
\text { management } \\
\text { - } \quad \text { Good understanding } \\
\circ \quad \text { flow } \\
\text { management } \\
\text { - } \quad \text { Limited understanding } \\
\circ \quad \text { void } \\
\quad \text { management } \\
\circ \quad \text { complex shape } \\
\text { forming }\end{array}$ & $\begin{array}{l}\text { - Include process and material } \\
\text { variability } \\
\text { - Focus on void formation and fibre } \\
\text { wrinkling issues } \\
\text { - Conformation in complex corners }\end{array}$ \\
\hline
\end{tabular}

\section{Prepreg design}

Over the last decade, research on OOA processing has led to a better understanding of the relationship between fibre bed architecture, resin thermochemical behaviour, air permeability and prepreg impregnation. As discussed in Section 1.3, several strategies can be used to manufacture OOA prepreg systems. The resulting resin impregnation levels and patterns can have a significant impact on the processibility of the prepreg. As shown in Grunenfelder, Dills, Centea, Nutt (2016), OOA prepreg can be specifically engineered to improve process robustness. The "USCpreg" format shown in Figure 25 features intentional dry gaps within the resin film, which impart substantially higher out-of-plane permeability. The resulting system is less sensitive than traditional OOA prepregs based on continuous but only partially impregnated resin films, and can achieve low levels of porosity in difficult processing conditions. This example illustrates that research should be focused on optimizing the prepreg structure for specific applications, as material requirements may differ depending on specific structural designs and manufacturing conditions.

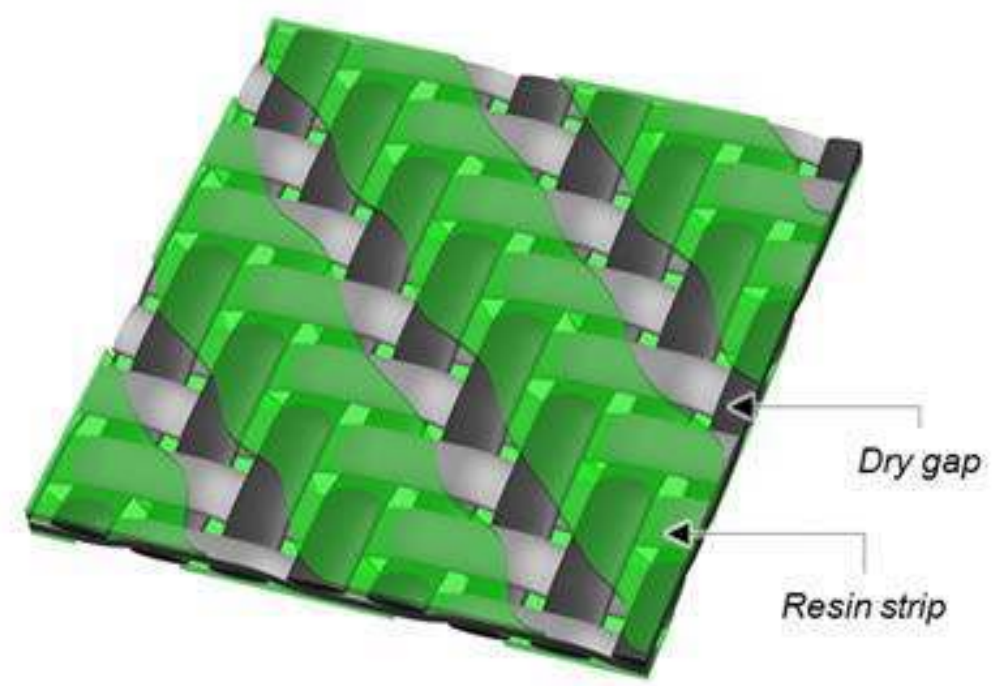

Figure 25 Schematic representation of the USCpreg format. 


\section{Prepreg inspection}

The control of the quality of the OOA prepreg material can only be achieved is a robust inspection technique is developed. As discussed in Section 2.2, several methods have been investigated to measure the level of impregnation of prepregs. More work is required in that area as small batch to batch variation in the prepreg impregnation quality can have a significant impact on the final part quality. A non destructive inspection system placed directly in the prepreging line could ensure that the produced material meets all the requirements (a concept is shown in Figure 26). Furthermore, improvement in the prepreging equipment can also result in a more detailed characterization of the prepreg initial state with more accurate inspection methods.

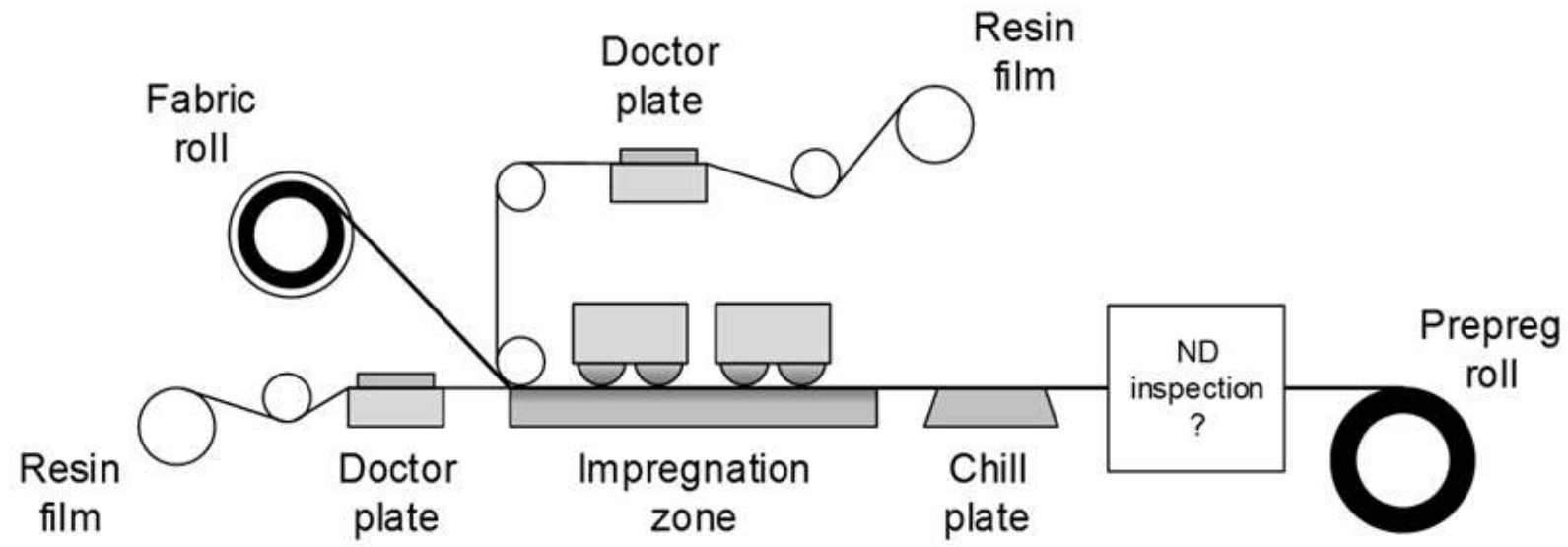

Figure 26 OOA prepreg online non destructive inspection system.

\section{Tooling and curing methods}

Section 2.6 presented the methods used to cure OOA and the tooling options. With OOA processing, the integration of the heating element in the tooling or the use of self-driven cure offer great potential to significantly reduce the energy costs. Additional benefits can also be a better control of the curing process which could be used to improve the final part quality and overall process robustness. The use of tooling made from additive manufacturing can also expand the flexibility of the process (Schniepp (2016)).

\section{Automation}

In many case, OOA processing is mostly a labour intensive process. OOA prepregs are offered for the automated fibre or tape placement process, which allow for a tailoring of the air permeability of the layup as gaps and overlaps can placed as specific location. Efforts on the automation of the layup process were discussed in Lukaszewicz, Ward, Potter (2012) where it was highlighted the future in layup automation will involve the participation of the research community, the equipment suppliers and the material manufacturers. As the current generation of automated machines were not necessarily designed with an adequate knowledge of the composite field.

\section{Design tools}


This chapter presented a review of the current design tools developed specifically for OOA processing. They can be used as a preliminary assessment for the process development of OOA parts. The research community builds on thirty years of composite processing science that produced a number of software platforms that can be used by material and process engineers. As OOA materials are in general more sensitive to process variations, new design tools that include process and material variability must be developed. For example, it was shown that by capturing the variability in the prepreg initial degree of impregnation, more representative porosity prediction were achieved (Helmus, Hubert, Hinterhoelzl (2015)). With the increase in computer power, stochastic methods can be implemented in order to solve more realistic processing problems. Nevertheless, we can say that over the last 10 years, significant steps on the science based processing of OOA prepreg were accomplished. It is possible today to develop an OOA process with quantitative tools supported by focused material characterization tests and scale-up test plans.

\section{References}

1. Advani SG, Sozer EM. (2011). Process modelling in composites manufacturing. Boca Raton, FL: CRC Press.

2. Bailleul J.-L, Delaunay D, Jarny Y. (1996). Determination of temperature variable properties of composite materials: methodology and experimental results. Journal of Reinforced Plastics and Composites 15(5), 479-496.

3. Bear J. (1972). Dynamics of fluids in porous media. New York: American Elsevier Pub. Co.

4. Boyard N. et al. (2003). Analysis and modelling of PVTX diagram of an unsaturated polyester resin, thermoplastic additive, and mineral fillers blend. Journal of Applied Polymer Science. 88, 1258-1267.

5. Boyard N. (2016). Heat Transfer in Polymer Composite Materials: Forming Processes. (N. Boyard, Ed.). Hoboken NJ: John Wiley \& Sons.

6. Brillant M, Hubert P. (2010). Out-of-Autoclave Processing of Complex Shape Laminates. In 54th International SAMPE Symposium and Exhibition. Seattle, WA.

7. Cender TA., Simacek P, Davis S, Advani S. (2016). Gas Evacuation from Partially Saturated Woven Fibre Laminates. Transport in Porous Media 115(3), 541-562.

8. Cender, T. A., Simacek, P., Advani, S. G. (2012). Degassing of a Partially Impregnated Fabric as a Function of Resin Saturation for Out-of-Autoclave Processing. In SAMPE. Baltimore.

9. Cender TA, Simacek P, Advani SG. (2013). Gas Permeability of Partially Saturated Fabrics. In Proc. 19th International Conference on Composite Materials (pp. 7237-7245).

10. Centea T, Hubert P. (2010) Measuring the impregnation of an out-of-autoclave prepreg by micro-CT. Composites Science and Technology 71, 593-599.

11. Centea T, Hubert P. (2012) Modelling the effect of material properties and process parameters on tow impregnation in out-of-autoclave prepregs. Composites Part A: Applied Science and Manufacturing 43, 1505-1513.

12. Centea T, Kratz J, Hubert P. (2012) The Effect of Out-Time and Cure Cycle on the Consolidation of Out-of-Autoclave Prepregs. Proc. 11th Int. Conf. Flow Process. Compos. Mater., Auckland, New Zealand.

13. Centea T, Hubert P. (2014) Out-of-autoclave prepreg consolidation under deficient pressure conditions. Journal of Composite Materials 48(16), 2033-2045. 
14. Centea T, Peters G, Nutt SR. (2015) Thermal gradients during out-of-autoclave prepreg cure: case study using a heated tool. Proc. SAMPE 2015 Tech Conf., Baltimore, MD: Society for the Advancement of Materials and Process Engineering.

15. Centea T, Grunenfelder LK, Nutt SR. (2015) A review of out-of-autoclave prepregs material properties, process phenomena and manufacturing considerations. Composites Part A: Applied Science and Manufacturing 70: 132-154.

16. Centea T, Nutt SR. (2016) Manufacturing cost relationships for vacuum bag-only prepreg processing. Journal of Composite Materials. 50(17): 2305-2321.

17. Centea, T., Hughes, S.-M., Payette, S., Kratz, J., Hubert, P. (2012). Scaling Challenges Encountered with Out-of-Autoclave Prepregs. In proceedings of the 53rd AIAA/ASME/ASCE/AHS/ASC Structures, Structural Dynamics and Materials Conference, Honolulu, HI.

18. Curiel T.M. Fernlund G. (2006). Stress build-up in bonded composite patch rRepair, In: Proceedings of the American Society for Composites Twentieth Technical Conference, Philadelphia, PA.

19. Daniel I.M., Wang T-M., Karalekas D., Gotro J.T. (1990). Determination of chemical cure shrinkage in composite laminates. Journal of Composites Technology \& Research 12930, 172-176.

20. Dietsch BA, Barnell TJ, Rauscher MD, Sutter JK, Pelham LI. (2014) No-oven, noautoclave composite tool fabrication. Proc. CAMX 2014 Conf., Orlando, FL: Society for the Advancement of Materials and Process Engineering.

21. Dullien FAL. (1979). Porous media : fluid transport and pore structure. New York: Academic Press.

22. Grove SM, Popham E, Miles ME. (2006). An investigation of the skin/core bond in honeycomb sandwich structures using statistical experimentation techniques. Composites Part A: Applied Science and Manufacturing 37(5), 804-12.

23. Grunenfelder LK, Nutt SR. (2010) Void formation in composite prepregs - Effect of dissolved moisture. Composites Science and Technology 70, 2304-2309.

24. Grunenfelder LK, Nutt SR. (2011) Air Removal in VBO Prepreg Laminates: Effects of Breathe-out Distance and Direction. Proc. 43rd Int. SAMPE Tech. Conf., Fort Worth, TX: Society for the Advancement of Materials and Process Engineering.

25. Grunenfelder LK, Centea T, Hubert P, Nutt SR. (2013) Effect of room-temperature outtime on tow impregnation in an out-of-autoclave prepreg. Composites Part A: Applied Science and Manufacturing 45, 119-126.

26. Grunenfelder LK, Dills A., Centea T, and Nutt SR. (2016) Effect of prepreg format on defect control in out-of-autoclave processing. Composites Part A: Applied Science and Manufacturing (In Press).

27. Haider M., Hubert P., Lessard L. (2007). Cure shrinkage characterization and modelling of a polyester resin containing low profile additives. Composites Part A: Applied Science and Manufacturing 38(3), 994-1009.

28. Helmus, R., Hubert, P., Hinterhoelzl, R. A. (2015). Stochastic Approach to Model Material Variation Determining Tow Impregnation in Out-of-Autoclave Prepreg. Composites Part A: Applied Science and Manufacturing 77, 293-300.

29. Hamill L, Centea T, Nutt SR. (2015) Surface porosity during vacuum bag-only prepreg processing: Causes and mitigation strategies. Composites Part A: Applied Science and Manufacturing 75, 1-10. 
30. Hill R., Muzumar S., Lee L. (1995). Analysis of volumetric changes of unsaturated polyester resins during curing. Polymer Engineering and Science 35, 852-859.

31. Huang, Y. et al. (1998). On-line monitoring of resin content for film impregnation process. Composites Science and Technology 58, 1531-1534.

32. Huang, Y., Sun, Y., Liu, L. (2003). Beta ray monitoring technique for control of resin content in continuous fibre prepreg materials. Materials Science and Technology 19, 815818.

33. Hughes S, Hubert P. Out-of-autoclave Prepreg Processing: Effect of Integrated Geometric Features on Part Quality, In Sampe 2013 Proceedings, Witchita, KS.

34. Jiang, B., Huang, Y. (2008). Quality inspection of laid fabric epoxy resins prepreg by near infrared spectroscopy. Composites Part A: Applied Science and Manufacturing 39, 712717.

35. Kamal MR, Sourour S. (1973). Kinetics and thermal characterization of thermoset cure. Polymer Engineering and Science 13(1), 59-64.

36. Khoun, L., Centea, T., Hubert, P. (2010). Characterization methodology of thermoset resins for the processing of composite materials - case study: CYCOM 890 RTM epoxy resin. Journal of Composite Materials 44(11), 1397-1415.

37. Kim D, Centea T, Nutt SR. (2014) Out-Time Effects on Cure Kinetics and Viscosity for an Out-Of-Autoclave (OOA) Prepreg: Modelling and Monitoring. Composites Science and Technology 100, 63-69.

38. Kim D, Centea T, Nutt SR. (2014) In-situ cure monitoring of an out-of-autoclave prepreg: effects of out-time on viscosity, gelation and vitrification. Composites Science and Technology 102, 132-138.

39. Kratz J, Hubert P. (2011) Processing out-of-autoclave honeycomb structures: Internal core pressure measurements. Composites Part A: Applied Science and Manufacturing 42(8), 1060-1065.

40. Kratz J, Hubert P. (2013). Anisotropic air permeability in out-of-autoclave prepregs: effect on honeycomb panel evacuation prior to cure. Composites Part A: Applied Science and Manufacturing 49,179-191.

41. Kratz J. et al. (2013) Thermal models for MTM45-1 and Cycom 5320 out-of-autoclave prepreg resins. Journal of Composite Materials 47(3), 341-352.

42. Kratz J, Hubert P. (2015) Vacuum bag only co-bonding prepreg skins to aramid honeycomb core. Part I. Model and material properties for core pressure during processing. Composites Part A: Applied Science and Manufacturing 72, 228-238.

43. Krumenacker N, Hubert P. (2015) Effect of Processing Deficiencies on Vacuum-Bag-Only Complex-Shape Prepreg Laminate Consolidation and Interlaminar Tensile Behaviour. ICCM20.

44. Levy, A., Stadlin, J., Hubert, P. (2014). Corner consolidation in vacuum bag only processing of out-of-autoclave composite prepregs laminates. In SAMPE. Seattle, WA, USA.

45. Levy A, Kratz J, Hubert P. (2015) Air evacuation during vacuum bag only prepreg processing of honeycomb sandwich structures: In-plane air extraction prior to cure. Composites Part A: Applied Science and Manufacturing. 68, 365-76.

46. Li C. et al. (2004). In-situ measurement of chemical shrinkage of MY750 epoxy resin. Composite Science and Technology 64, 55-64. 
47. Li, W., Huang, Y.D., Liu, L., Chen, N.T. (2005). Rapid and nondestructive analysis of quality of prepreg cloth by near-infrared spectroscopy. Composites Science and Technology 65, 1668-1674.

48. Li, W. et al. (2006). The application of near infrared spectroscopy in the quality control analysis of glass/phenolic resin prepreg. Journal of Materials Science 41, 7183-7189.

49. Louis BM, Hsiao K, Fernlund G. (2010). Gas Permeability Measurements of Out of Autoclave Prepreg MTM45-1/CF2426A. Proc. SAMPE 2010 Conf., Seattle, WA: Society for the Advancement of Materials and Process Engineering.

50. Lucas, S, Howard S, Senger J (2010) Vacuum Bag Only Processing: Improving Prepreg Out-Time and Porosity for Large Composite Structure. Proc. SAMPE 2010 Conf., Seattle, WA: Society for the Advancement of Materials and Process Engineering.

51. Lukaszewicz, H.-J.A., Ward, C., Potter, K.D. (2012). The engineering aspects of automated prepreg layup: History, present and future. Composites Part B: Engineering 43(3), 9971009.

52. Nawab Y, Casari P, Boyard N. Jacquemin, F. (2013). Characterization of the cure shrinkage, reaction kinetics, bulk modulus and thermal conductivity of thermoset resin from a single experiment. Journal of Material Science 48, 2394-2403.

53. Palardy-Sim, M., Hubert, P. (2015). Characterization of the degree of impregnation of outof-autoclave prepreg. Processings of the 20th International Conference on Composite Materials (ICCM-20), Copenhagen, Denmark.

54. Payette S, Smith AW, Hubert P, Goyette K, Kazanas C. (2015) Out-of-Autoclave Manufacturing: Benchmarking of an Integrally Heated Tool-plate. SAMPE Journal 2015. 51(1), 27-35.

55. Peltonen, P., Järvelä, P. (1992). Methodology for determining the degree of impregnation from continuous glass fibre prepreg. Polymer Testing 11, 215-224.

56. Rion J, Stutz S, Leterrier Y, Manson J-AE. (2009) Influence of process pressure on local facesheet instability for ultra-light sandwich structures. Journal of Sandwich Structures and Materials. 11(4), 293-311.

57. Ruiz E., Trochu F. (2005). Thermomechanical properties during cure of glass-polyester RTM composites: elastic and viscoelastic modelling. Journal of Composite Materials 39(10), 881-916.

58. Schniepp, T.J. (2016). Design Guide Development for Additive Manufacturing (FDM) of Composite Tooling. In proceedings of the Conference: SAMPE 2016 - Long Beach CA.

59. Schoch K.F., Panackal P.A., Franck P.P. (2004). Real-time measurement of resin shrinkage during cure. Thermomech Acta 417, 115-118.

60. Simacek P, Advani SG. (2004) Desirable features in mold filling simulations for liquid composite moulding processes. Polymer Composites. 25(4), 355-67.

61. Tavares SS, Michaud V, Manson JA. (2009). Through thickness air permeability of prepregs during cure. Composites Part A: Applied Science and Manufacturing 40(10), $1587-1596$.

62. Tavares SS, Caillet-Bois N, Michaud V, Manson JAE. (2010A). Vacuum-bag processing of sandwich structures: Role of honeycomb pressure level on skin-core adhesion and skin quality. Composites Science and Technology. 70(5), 797-803.

63. Tavares SS, Caillet-Bois N, Michaud V, Manson JAE. (2010B) Non-autoclave processing of honeycomb sandwich structures: Skin through thickness air permeability during cure. Composites Part A: Applied Science and Manufacturing. 41(5),646-652. 
64. Thomas C.L., Bur A.J. (1999). In-situ monitoring of product shrinkage during injection moulding using an optical sensor. Polymer Engineering and Science 39(9), 1619-1627.

65. Thomas, S., Bongiovanni, C., Nutt, S. (2008). In situ estimation of through-thickness resin flow using ultrasound. Composites Science and Technology 68, 3093-3098.

66. Thomas, S., Nutt, S. (2009). Temperature dependence of resin flow in a resin film infusion (RFI) process by ultrasound imaging. Applied Composite Materials 16, 183-196.

67. Tong R (2012) Cost Analysis on L-Shape Composite Component Manufacturing. Concordia University.

68. Vallittu, P. (1995). Impregnation of glass fibres with polymethylmethacrylate using a powder-coating method. Applied Composite Materials 2, 51-58.

69. Watts D.C., Cash J.E. (1991). Kinetic measurements of photo-polymerization contraction in resins and composites. Measurement Science \& Technology 2, 788-794.

70. Witik RA, Gaille F, Teuscher R, Ringwald H, Michaud V, Månson J-AE. (2012) Economic and environmental assessment of alternative production methods for composite aircraft components. Journal of Cleaner Production. (29-30): 91-102.

71. Wysocki M, Larsson R, Toll S. (2009) Modelling the Consolidation of Partially Impregnated Prepregs. Proc. 17th Int. Conf. Compos. Mater., Edinburgh, Scotland: International Commitee on Composite Materials.

72. Ye, L., Klinkmuller, V., Friedrich, K. (1992). Impregnation and consolidation in composites made of GF/PP powder impregnated bundles. Journal of Thermoplastic Composite Materials 5, 32-48.

73. Yu H., Mhaisalkar S.G., Wong E.H. (2005). Cure shrinkage measurement of nonconductive adhesives by means of a thermomechanical analyzer. Journal of Electronic Materials 34, 1177-1182. 